\title{
RESEARCH
}

\section{Gender and interpretation in Greek: Comments on Merchant (2014)}

\author{
Yasutada Sudo and Giorgos Spathas ${ }^{2}$ \\ ${ }^{1}$ University College London, London, UK \\ 2 Leibniz-Zentrum Allgemeine Sprachwissenschaft, Berlin, DE \\ Corresponding author: Yasutada Sudo (y.sudo@ucl.ac.uk)
}

\begin{abstract}
Merchant (2014, "Gender mismatches under nominal ellipsis", Lingua, 151: 9-32) makes the following two claims about nominal ellipsis in (Modern) Greek. (i) There are three classes of MASCULINE-FEMININE noun pairs that differ in whether nominal ellipsis with gender mismatch is possible. (ii) Nominal ellipsis with gender mismatch is possible in predicative positions but not in argument positions. We take issue with both of these claims. Our qualms about (i) are relatively minor. It appears that his primary data are hard to replicate, but we present novel sets of data involving focus constructions that also demonstrate that Greek has three classes of MASCULINE-FEMININE noun pairs. As for (ii), we argue that it is empirically inaccurate and nominal ellipsis with gender mismatch is in fact possible in argument positions as well. This is problematic for the analysis Merchant develops, as it is tailored to derive (ii). Furthermore, we argue that his analysis does not give a straightforward account of our observations about focus constructions. We put forward an alternative account of the interpretation of gendered nouns according to which there are three types of nouns with gender inferences: (a) those that have gender inferences in both assertive and presuppositional dimensions of meaning, (b) those that only have gender inferences in the presuppositional dimension of meaning, and (c) those that do not have gender inferences in their semantics but through competition with the opposite gender (gender competition).
\end{abstract}

Keywords: gender; focus; ellipsis; presupposition; Greek

\section{Introduction}

In this paper we will analyze the interpretation of gender-marking on nouns in (Modern) Greek. In order to minimize confusion, we will adopt the following terminological convention. We distinguish 'gender' in the biosociological sense and 'gender' in the grammatical sense, by writing the latter as 'GENDER' (the former will remain 'gender'). Similarly, we write 'FEMININE', 'MASCULINE', 'EPICENE', when we use these terms in the grammatical sense.

All nouns in Greek trigger GENDER agreement/concord with items such as determiners and adjectives. ${ }^{1}$ We distinguish cases where the GENDER marking is interpreted and cases where it is not. We call them 'interpreted GENDER' and 'uninterpreted GENDER', respectively. For instance, thalasa 'sea' in Greek is a FEMININE noun, triggering FEMININE agreement with determiners and adjectives, but this GENDER assignment does not seem to have any interpretive effect. Therefore this is a case of uninterpreted GENDER.

\footnotetext{
${ }^{1}$ Note that GENDER and noun declension classes are to be distinguished, because in the general case, neither uniquely determines the other. We will therefore define GENDER in terms of agreement. See Corbett (1991) and Kramer (2015) among others for more discussion.
} 
For nouns denoting humans, the overwhelming tendency is that GENDER correlates with some gender inference. ${ }^{2}$ For example, the MASCULINE noun adherfos and the FEMININE noun adherfi not only share the morphological root adherf-, but also a semantic core in that both describe siblings, with the sole interpretive difference being the gender: adherfos means 'male sibling' or 'brother', and adherfi means 'female sibling' or 'sister'. These are, therefore, cases of interpreted GENDER. They also trigger obligatory GENDER agreement with determiners and adjectives on a par with other nouns with interpreted or uninterpreted GENDER in this language, as illustrated by (1). Unless otherwise noted we use * to indicate unacceptability (and not necessarily syntactic ungrammaticality) throughout this paper.
a. O Petros episkefthike enan/*mia arosto/*arosti adherfo tu. the Petros visited a.M/*a.F sick.M/*sick.F sibling.M his 'Petros visited a male sibling of his.'
b. O Petros episkefthike *enan/mia *arosto/arosti adherfi tu. the Petros visited *a.M/a.F *sick.M/sick.F sibling.F his 'Petros visited a female sibling of his.'

There are also cases of uninterpreted GENDER among human-denoting nouns, e.g. koritsi 'girl' triggers NEUTER agreement. However, in Greek, uninterpreted GENDER is an exception, rather than the rule, and there is no morphologically related pair of MASCULINE and FEMININE nouns in Greek, where the MASCULINE noun describes female individuals or the FEMININE noun describes male individuals. We will mostly focus on human-denoting nouns with interpreted GENDER in this paper, as our goal is to investigate the interpretation of GENDER in Greek (see Ralli 2002; Pavilidou 2015; Markopolous 2018 and references there in for other studies on GENDER in Greek).

In addition to noun pairs like adherfos-adherfi that contrast in GENDER, Greek has a class of nouns that only have one form but can trigger MASCULINE or FEMININE agreement on determiners and adjectives, depending on the gender of the individual(s) they are used to describe. Such nouns are called 'EPICENE nouns'. For example, jatros 'doctor' is an EPICENE noun. As shown in (2), it is compatible with FEMININE or MASCULINE determiners and adjectives, and the agreement marking on determiners and adjectives affects the interpretation, as indicated below. ${ }^{3}$
a. O Petros episkefthike enan kalo jatro. the Petros visited a.M good.M doctor 'Petros visited a good male doctor.'
b. O Petros episkefthike mia kali jatro. the Petros visited a.F good.F doctor 'Petros visited a good female doctor.'

\footnotetext{
${ }^{2}$ Animate but non-human-denoting nouns-nouns denoting (higher) animals and other animates, especially those that describe tamed animals-have additional complications, and we stay away from them in this paper (but see Section 6.5). We develop a detailed analysis of such nouns in Greek in a separate paper, Spathas \& Sudo (to appear), based on our proposal in this paper.

${ }^{3}$ As an anonymous reviewer for Glossa pointed out, FEMININE forms of epicene nouns can be formed with a derivational suffice, e.g. jiatrina. This derivational suffix -ina is particularly productive. As we do not delve into the internal structure of nouns with GENDER in this paper, we do not discuss it, but we put forward an analysis of suffixes like -ina in a separate paper, Spathas \& Sudo (to appear).
} 
Although GENDER specification is not morphologically visible on EPICENE nouns (and we will eventually analyze them as semantically gender-neutral), we include EPICENE nouns as cases of interpreted GENDER, as GENDER, as reflected on agreement, has semantic consequences.

The main focus of the present paper is the interpretation of nouns like adherfos-adherfi and jatros. In particular, we closely examine Merchant's (2014) data and analysis of nominal ellipsis involving such nouns. His main empirical claims are the following.

(i) There are three classes of MASCULINE-FEMININE noun pairs that differ in whether nominal ellipsis involving GENDER mismatch is possible.

(ii) Nominal ellipsis with GENDER mismatch is only attested in predicative positions and never in argument positions.

We take issue with both of these claims. Our qualms about (i) are relatively minor: It turns out that his primary data are hard to replicate. However, we will present novel sets of data from focus constructions that demonstrate that Greek indeed has three classes of morphologically related MASCULINE-FEMININE noun pairs. As for (ii), we argue that it is empirically inaccurate and observe that nominal ellipsis in predicative and argument positions behave similarly with respect to GENDER mismatch. This is problematic for the analysis Merchant develops, as it is tailored to derive the putative predicative vs. argument asymmetry. Furthermore, we argue that his analysis does not straightforwardly explain our observations about GENDERed nouns in focus constructions.

In order to analyze the data from focus constructions, we put forward an alternative analysis of nouns with interpreted GENDER. In particular, we argue that there are three ways in which GENDER gives rise to gender inferences:

- GENDER gives rise to a gender inference in both asserted and presupposed dimensions of meaning;

- GENDER gives rise to a gender inference only in the presupposed dimension of meaning;

- GENDER does not have a gender inference in the semantics, but ends up having one via competition with the interpretation of a different GENDER (gender competition).

We show that this three-way classification is necessary and sufficient to account for the data from focus constructions and specify the minimal syntactic machinery needed to implement it. In doing so, we will not commit ourselves to any specific proposal about the internal syntactic structure of nouns with GENDER, although some possibilities will be mentioned and discussed when necessary. This is a very actively researched area in the current literature (Wechsler \& Zlatić 2003; Matushansky 2013; Kramer 2015; Kučerová 2018; Murphy et al. 2018; Pesetsky 2013; Puškar 2017; 2018), but our analysis of GENDERed nouns in focus constructions in Greek does not require explicit commitments on this theoretical issue. We address some syntactic questions arising from our proposal in this paper in a separate paper, Spathas \& Sudo (to appear). Likewise, we have very little to say about uninterpreted GENDER in the current paper, and we refer the interested reader to the same paper (Spathas \& Sudo to appear). A more fine-grained syntactic analysis is also presumably necessary for an account of GENDER in nominal ellipsis, both in Greek and other languages that have been studied in this domain (Bobaljik \& Zocca 2011; Murphy et al. 2018; Sprouse et al. 2018). Since, however, our observations reveal that the judgments in Greek are not stable in some crucial cases, as we will discuss, and languages seem to be non-trivially different in this domain, we will not be committed to a specific analysis 
of nominal ellipsis in Greek or other languages. In order to develop a formal analysis of ellipsis with mismatching GENDER in Greek, we suspect that more quantitative data that reveal the nature of the unstable judgments are necessary, and we hope to tackle this issue and cross-linguistic variation in further work. Nevertheless, we discuss shortly the Greek data on nominal ellipsis in the light of the data from focus constructions and their analysis and make a first suggestion on how to address at least some of the issues that arise in that domain.

The organization of the present paper is as follows. We will review Merchant's (2014) evidence for three classes of nouns with GENDER in Section 2, and raise additional data, including data involving focus constructions. In Section 3, we will critically review Merchant's (2014) claims about nominal ellipsis in argument positions. Then in Section 4, we will argue that his theory cannot account for our observations about focus constructions, and propose our own analysis in Section 5. We will conclude and discuss further issues, including some more details of the aforementioned further questions that arise from our claims in Section 6.

\section{Three classes of nouns with GENDER in Greek}

\subsection{Merchant's data of nominal ellipsis}

Merchant (2014) claims that there are three groups of human-denoting MASCULINE-FEMININE noun pairs in Greek, according to whether nominal ellipsis with GENDER mismatch is possible. More concretely, based on data from predicative uses of relevant nouns, he puts forward the following classification:

- For Class I nouns like adherfos 'brother' vs. adherfi 'sister', nominal ellipsis with mismatching GENDER is unacceptable with a MASCULINE or FEMININE antecedent;

- EPICENE nouns like jatros 'doctor', which constitute Class II, allow for nominal ellipsis with GENDER mismatches with a MASCULINE or FEMININE antecedent; EPICENE

- For Class III nouns like dhaskalos vs. dhaskala 'teacher', nominal ellipsis with GENDER mismatch is grammatical when the antecedent is MASCULINE but not when the antecedent is FEMININE.

Relevant examples are reproduced below from Merchant (2014) (his (9), (22) and (25), respectively). In these examples, the intended gender of the elided noun is visible on the determiner (D) and adjective (A). The supposed elided phrases are indicated throughout the paper as ELLIPSIS (although as we will see in Section 4, Merchant claims that these cases involve a proform, rather than deletion). The judgments are as reported in Merchant (2014). ${ }^{4}$

a. *O Petros ine kalos adherfos, ala i Maria ine mia kakia adherfi. the Petros is good.M brother.M but the Maria is a.F bad.F (sister) (intended) 'Petros is a good brother, but Maria is a bad (sister).'

b. *I Maria ine kali adherfi, ala o Petros ine enas kakos adherfos. the Maria is good.F sister.F but the Petros is a.M bad.M (brother) (intended) 'Maria is a good sister, but Petros is a bad (brother).'

\footnotetext{
${ }^{4}$ The acceptable sentences below seem to be somewhat degraded in comparison to corresponding examples with matching GENDER (relevant examples are not included here, but see (11) in Merchant (2014), for example). But the same contrast persists even without nominal ellipsis, suggesting that it is due to an extra factor. Since this subtle difference is not of our main concern, it is left unmarked here.
} 
(4) a. O Petros ine kalos jatros, ala i Maria ine mia kakia jatros. the Petros is good.M doctor but the Maria is a.F bad.F (doctor) 'Petros is a good doctor, but Maria is a bad one.'

b. I Maria ine kali jatros, ala o Petros ine enas kakos jatros. the Maria is good.F doctor but the Petros is a.M bad.m (doctor) 'Maria is a good doctor, but Petros is a bad one.'

(5) a. O Petros ine kalos dhaskalos, ala i Maria ine mia kakia dhaskala. the Petros is good.M teacher.M but the Maria is a.F bad.F (teacher.F) 'Petros is a good teacher, but Maria is a bad one.'

b. *I Maria ine kali dhaskala, ala o Petros ine enas kakos thaskalos. the Maria is good.F teacher.F but the Petros is a.M bad.m (teacher.M) (intended) 'Maria is a good teacher, but Petros is a bad one.'

Noting potential inter-speaker variation (see also Bobaljik \& Zocca 2011 for a related remark about Brazilian Portuguese), Merchant (2014) lists the following nouns as examples of the three classes. ${ }^{5}$

(6)

$\begin{array}{llll}\begin{array}{l}\text { Class I } \\ \text { kirios }\end{array} & \text { 'gentleman' } & \text { kiria } & \text { 'lady' } \\ \text { antras } & \text { 'man, husband' } & \text { jineka } & \text { 'woman, wife' } \\ \text { ksadherfos } & \text { 'male cousin' } & \text { ksadherfi } & \text { 'female cousin' } \\ \text { engonos } & \text { 'nephew' } & \text { engoni } & \text { 'niece' } \\ \text { vaftistikos } & \text { 'godson' } & \text { vaftistikia } & \text { 'goddaughter' } \\ \text { prinkipas } & \text { 'prince' } & \text { prinkipissa } & \text { 'princess' } \\ \text { vasilias } & \text { 'king' } & \text { vasilissa } & \text { 'queen' } \\ \text { aftokratoras } & \text { 'emperor' } & \text { aftokratira } & \text { 'empress' }\end{array}$

(7) Class II

antipalos 'opponent', apostoleas 'sender', asthenis 'patient/sick person', astinomikos 'police officer', dhiermineas 'interpreter', dhikastis 'judge', dhikigoros 'lawyer', dhimosiografos 'journalist', epangelmatias 'professional', epistimonas 'scientist', filologos 'philologist', fisikos 'physicist', glossologos 'linguist', goneas 'parent' gramateas 'secretary', idhravlikos 'plumber', iereas 'priest/pastor', ithopios 'actor', ipalilos 'employee', ipurgos 'minister', istorikos 'historian'

(8)

$\begin{array}{lll}\begin{array}{l}\text { Class III } \\ \text { mathtis } \\ \text { pianistas }\end{array} & \begin{array}{l}\text { mathitria } \\ \text { pianistria }\end{array} & \begin{array}{l}\text { 'pupil' } \\ \text { tragudhistis }\end{array} \\ \text { tragudhistria } & \text { 'singer' } \\ \text { theos } & \text { thea } & \text { 'god' } \\ \text { nosokomos } & \text { nosokoma } & \text { 'nurse' } \\ \text { katharistis } & \text { katharistria } & \text { 'cleaner' } \\ \text { kathijitis } & \text { kathijitria } & \text { 'professor' } \\ \text { fititis } & \text { fititria } & \text { 'student' } \\ \text { thios } & \text { thia } & \text { 'uncle, aunt' } \\ \text { nonos } & \text { nona } & \text { 'godfather/godmother' }\end{array}$

${ }^{5}$ Among Merchant's Class I nouns, the pair andras-jineka do not share a morphological root. This might be due to suppletion, but there is no indication that any such pair with distinct roots allow nominal ellipsis in Greek. Thus, this might not be a relevant pair here. 
We would like to point out, however, that the judgments of these sentences do not seem to be as clean as reported in Merchant (2014). Upon finding some variability among speakers, we closely consulted 8 native speakers of Greek, and also conducted an informal questionnaire with 16 native speaker linguists, but failed to reliably replicate the above patterns. In particular, while the judgments about Class I and Class II nouns seem to be clear and replicable to some extent, the asymmetry between the MASCULINE and FEMININE antecedents with Class III nouns was not constantly found, and for many of our consultants, even when there is a contrast, it does not seem to be very prominent. Furthermore, as noted above, there seems to be inter-speaker variation as to which nouns belong to Class I or Class III, and we found no pair of MASCULINE-FEMININE nouns that showed a reliable asymmetric pattern that persisted across speakers.

Part of the reason why we failed to replicate these results might be due to the fact that none of the sentences above are perfectly natural, which is largely due to the presence of an indefinite article only in the second conjunct, a factor Merchant himself acknowledges as a potential confound. He explains that the indefinite article is included in these and other examples in his paper, despite the somewhat degraded status, because without it the second sentence would preferentially receive a predicative adjectival reading (which is akin to 'Mary is bad', rather than 'Mary is a bad one') and would not involve nominal ellipsis. Also, adding an indefinite article in the first sentence would result in an identity reading, rather than the intended predicational reading, and is also somewhat unnatural.

We therefore suspect that the unnaturalness of the examples contributed to our failing to replicate the judgments he reports, but at the same time, we have reasons to think that that does not explain everything. Specifically, we will see in Section 3 that nominal ellipsis is possible in argument position as well, contrary to Merchant's claim, where we do not have analogous concerns about unnaturalness. Nonetheless, we failed to find a pair of gendered nouns that exhibited a reliable contrast between MASCULINE and FEMININE antecedents even with such sentences.

For these reasons, we think Merchant's (2014) data involving nominal ellipsis do not constitute conclusive evidence for his classification of noun-pairs with interpreted GENDER in Greek. This of course does not mean that his classification needs to be rejected, as there are several possible reasons for our failure to replicate his results. Also, Bobaljik \& Zocca (2011) present similar patterns in other languages, which suggests that what Merchant observed had some truth to it. While we are unable to pin down the exact reasons why the data turned out to be not as clear as we expected, we will raise further data involving focus constructions that support essentially the same classification of noun pairs with interpreted GENDER in Greek and that received relatively stable judgments among the 16 speakers we consulted.

\subsection{Focus constructions}

To show that there are indeed three classes of nouns with GENDER in Greek, we will make use of focus constructions. Focus constructions involve reference to alternatives, and depending on the noun, the alternatives might or might not have to refer to the gender inference. Consider first the following examples involving Class I nouns, adherfos and adherfi, and observe that they lack inferences about the opposite gender.

a. Mono o Petros ine adherfos tu Jani. only the Petros is sibling.M the.GEN Janis.GEN 'Only Petros is a brother of Janis'.' 
b. Mono i Maria ine adherfi tu Jani. only the Maria is sibling.F the.GEN Janis.GEN 'Only Maria is a sister of Janis'.' $\quad \nRightarrow$ Petros is not Janis's brother

These examples can be understood as cases where the focus alternatives must involve the gender inference. That is, mono 'only' negates the focus alternatives in these sentences, and the focus alternative all look like 'Maria is Janis's male sibling' and 'Petros is Janis's female sibling', respectively. Consequently, if the gender of the subject of an alternative sentence does not match the gender of the noun, then the falsity of the alternative sentence is trivial.

On the other hand, Class II nouns do give rise to inferences about the opposite gender in the same construction.

a. Mono o Petros ine kalos jatros. only the Petros is good.M doctor 'Only Petros is a good doctor.'

$\Rightarrow$ Maria is not a good doctor

b. Mono i Maria ine kali jatros. only the Maria is good.F doctor 'Only Maria is a good doctor.'

$\Longrightarrow$ Petros is not a good doctor

Here the focus alternatives are oblivious to the gender information, and consequently alternatives like 'Maria/Petros is a good doctor' are negated, regardless of the GENDER marking in the sentence.

Crucially, we observe an asymmetry with Class III nouns like dhaskalos-dhaskala where the MASCULINE gives rise to an inference about female individuals, while the FEMININE does not give rise to an inference about male individuals.

a. Mono o Petros ine dhaskalos.

only the Petros is teacher.M

'Only Petros is a teacher.'

$\Longrightarrow$ Maria is not a teacher

b. Mono i Maria ine dhaskala. only the Maria is teacher.F

'Only Maria is a teacher.'

$\nRightarrow$ Petros is not a teacher

Other focus constructions point to the same conclusions, including superlatives, ordinals and nominal only. In order to save space, we will only present data involving superlatives here. In the superlative construction of the form the best $N$, Class I nouns give rise to readings that only compare individuals with the same gender. ${ }^{6}$

a. O Petros ine o kaliteros adherfos tu Jani.

the Petros is the.M best.M sibling.M the.GEN Janis.GEN

'Petros is the best brother of Janis' (among Janis' brothers).'

\footnotetext{
${ }^{6}$ Yatsushiro \& Sauerland (2006) observe that German FEMININE nouns give rise to ambiguity in sentences like (12); they can behave like adherfi or like dhaskalos. The Greek example in (12b) is unambiguous. Kučerová (2018) develops an interesting account of the ambiguity in German, proposing that it depends on the Spell-Out/Transfer timing. As far as we can see, her analysis is compatible with our Greek data, on the assumption that interpreted FEMININE in Greek always affects the interpretation. Note also that Kučerová (2018) does not make the distinction between asserted and presupposed gender, but her account could potentially incorporate it.
} 
b. I Maria ine i kaliteri adherfi tu Jani. the Maria is the.F best.F sibling.F the.GEN Janis.GEN 'Maria is the best sister of Janis' (among Janis' sisters).'

On the other hand, Class II nouns give rise to readings where the comparison is across individuals of both genders.

a. O Petros ine o kaliteros jatros. the Petros is the.M best.M doctor 'Petros is the best doctor (among the male and female doctors).'

b. I Maria ine i kaliteri jatros. the Maria is the.F best.F doctor 'Maria is the best doctor (among the male and female doctors).'

With Class III nouns, we observe a crucial asymmetry such that the MASCULINE nouns give rise to a reading with gender-neutral comparison like Class II nouns, and the FEMININE noun gives rise to a reading with gender-separated comparison like Class I nouns.

a. O Petros ine o kaliteros dhaskalos.

the Petros is the.M best.M teacher.M

'Petros is the best teacher (among the male and female teachers).'

b. I Maria ine i kaliteri dhaskala. the Maria is the.F best.F teacher.F 'Maria is the best teacher (among the female teachers).'

These are consistent with the patterns we observed with mono 'only' above.

Using these tests, we can identify essentially the same three classes of nouns with interpreted GENDER in Greek that Merchant (2014) proposes. It seems to us that our diagnostics with focus constructions are more reliable and yield results that are more consistent across speakers, although, as we remarked above, the reason why the ellipsis data are not so clear remains a mystery for now. Furthermore, these data involving focus constructions not only show the same empirical point as Merchant (2014) but also pose a challenge for his theory, as we will discuss in Section 4.

\section{The putative predicate vs. argument asymmetry}

In addition to identifying the three classes of MASCULINE-FEMININE noun pairs, Merchant (2014) claims that nominal ellipsis with gender mismatch is only attested in predicative positions and not in argument positions. We will show in this section that this generalization is not empirically warranted.

Merchant's claim about the unavailability of nominal ellipsis with GENDER mismatches in argument positions in Greek is based on the following examples (adapted from his (10), (23), and (26)). All of them are unacceptable.

a. *O Petros exi enan adherfo stin Veria, ala dhen exi mia adherfi the Petros has a.M brother in.the Veria but not has one.F (sister) stin Katerini.

in.the Katerini

(intended) 'Petros has a brother in Veria, but he doesn't have one (sister) in Katerini.' 
b. *O Petros exi mia adherfi stin Veria, ala dhen exi enan adherfo the Petros has a.F sister in.the Veria but not has one.M (brother) stin Katerini. in.the Katerini (intended) 'Petros has a sister in Veria, but he doesn't have one (brother) in Katerini.'

a. *O Petros exi enan jatro stin Veria, ala dhen exi mia jatro the Petros has a.M doctor in.the Veria but not has one.F (doctor) stin Katerini. in.the Katerini (intended) 'Petros has a male doctor in Veria, but he doesn't have one (female doctor) in Katerini.'

b. *O Petros exi mia jatro stin Veria, ala dhen exi enan jatro the Petros has a.F doctor in.the Veria but not has one.M (doctor) stin Katerini. in.the Katerini (intended) 'Petros has a female doctor in Veria, but he doesn't have one (male doctor) in Katerini.'

a. *O Petros exi enan dhaskalo stin Veria, ala dhen exi mia the Petros has a.M teacher.M in.the Veria but not has one.F dhaskala stin Katerini. (teacher.F) in.the Katerini (intended) 'Petros has a male teacher in Veria, but he doesn't have one (female teacher) in Katerini.'

b. *O Petros exi mia dhaskala stin Veria, ala dhen exi enan the Petros has a.F teacher.F in.the Veria but not has one.M dhaskale stin Katerini. (teacher.M) in.the Katerini (intended) 'Petros has a female teacher in Veria, but he doesn't have one (male teacher) in Katerini.'

Importantly, when the nouns are of the same GENDER, the judgments improve, as shown by the following examples (adapted from Merchant's (12), (13), (32), (33), and (34)).

(18) a. O Petros exi enan adherfo stin Veria, ala dhen exi enan adherfo the Petros has a.M brother in.the Veria but not has one.M (brother) stin Katerini. in.the Katerini 'Petros has a brother in Veria, but he doesn't have one (brother) in Katerini.'

b. O Petros exi mia adherfi stin Veria, ala dhen exi mia adherfi the Petros has a.F sister in.the Veria but not has one.F (sister) stin Katerini. in.the Katerini 'Petros has a siter in Veria, but he doesn't have one (sister) in Katerini.' 
a. O Petros exi enan kalo adherfo, ala dhen exi enan kako the Petros has a.m good.m brother but not has one.M bad.M adherfo.

(brother)

'Petros has a good brother but he doesn't have a bad one (brother).'

b. O Petros exi mia kali adherfi, ala dhen exi mia kakia adherfi. the Petros has a.F good.F sister, but not has one.F bad.F (sister) 'Petros has a good sister but he doesn't have a bad one (sister).'

These data led Merchant to conclude that ellipsis with GENDER mismatches is unavailable across the board, if the relevant noun is in an argument position. We would like to argue that this conclusion is too hasty, and point out the possibility that the examples with GENDER mismatches in (15)-(17) are unacceptable for reasons independent of nominal ellipsis.

That their unacceptability is not due to nominal ellipsis is strongly suggested by the fact that the non-elliptical versions of the sentences are in fact all unacceptable, as shown below. $^{7}$

(20) a. *O Petros exi enan adherfo stin Veria, ala dhen exi mia adherfi the Petros has a.M brother in.the Veria but not has one.F sister stin Katerini.

in.the Katerini

(intended) 'Petros has a brother in Veria, but he doesn't have a sister in Katerini.'

b. *O Petros exi mia adherfi stin Veria, ala dhen exi enan adherfo the Petros has a.F sister in.the Veria but not has one.M brother stin Katerini. in.the Katerini (intended) 'Petros has a sister in Veria, but he doesn't have a sister in Katerini.'

(21) a. *O Petros exi enan jatro stin Veria, ala dhen exi mia jatro the Petros has a.M doctor in.the Veria but not has one.F doctor stin Katerini.

in.the Katerini (intended) 'Petros has a male doctor in Veria, but he doesn't have a female doctor in Katerini.'

b. *O Petros exi mia jatro stin Veria, ala dhen exi enan jatro the Petros has a.F doctor in.the Veria but not has one.M doctor stin Katerini.

in.the Katerini

(intended) 'Petros has a female doctor in Veria, but he doesn't have a male doctor in Katerini.'

\footnotetext{
${ }^{7}$ Merchant (2014) presents the same sentences as acceptable (his (32)-(34)), but we could not replicate these results with our informants or native-speaker anonymous reviewers, for whom the following sentences are as unacceptable as their elliptical counterparts.
} 
a. *O Petros exi enan dhaskalo stin Veria, ala dhen exi mia dhaskala the Petros has a.M teacher.M in.the Veria but not has one.F teacher.F stin Katerini.

in.the Katerini

(intended) 'Petros has a male teacher in Veria, but he doesn't have a female teacher in Katerini.'

b. *O Petros exi mia dhaskala stin Veria, ala dhen exi enan dhaskalo the Petros has a.F teacher.F in.the Veria but not has one.M teacher.M stin Katerini. in.the Katerini (intended) 'Petros has a female teacher in Veria, but he doesn't have a male teacher in Katerini.'

There seem to be two problems with these sentences. Firstly, under the scope of clause-mate negation, as in the second conjuncts of these sentences, the use of the negative concord indefinite determiners, kanenan and kamia, instead of plain indefinite determiners, enan and mia, is almost obligatory. Changing the determiners does not make the sentences fully acceptable, however. Rather, making the second conjunct positive does, as in (23)-(25). ${ }^{8}$

(23) a. O Petros exi enan adherfo stin Veria, ke exi mia adherfi stin the Petros has a.M brother in.the Veria and has one.F sister in.the Katerini.

Katerini

'Petros has a brother in Veria, and he has a sister in Katerini.'

b. O Petros exi mia adherfi stin Veria, ke exi enan adherfo stin the Petros has a.F sister in.the Veria and has one.M brother in.the Katerini.

Katerini

'Petros has a sister in Veria, and he has a sister in Katerini.'

(24) a. O Petros exi enan jatro stin Veria, ke exi mia jatro stin the Petros has a.M doctor in.the Veria and has one.F doctor in.the Katerini.

Katerini

'Petros has a male doctor in Veria, and he has a female doctor in Katerini.'

b. O Petros exi mia jatro stin Veria, ke exi enan jatro stin the Petros has a.F doctor in.the Veria and has one.M doctor in.the Katerini.

Katerini

'Petros has a female doctor in Veria, and he has a male doctor in Katerini.'

(25) a. O Petros exi enan dhaskalo stin Veria, ke exi mia dhaskala the Petros has a.M teacher.M in.the Veria and has one.F teacher.F stin Katerini. in.the Katerini

'Petros has a male teacher in Veria, and he has a female teacher in Katerini.'

\footnotetext{
${ }^{8}$ Two anonymous reviewers for Natural Language and Linguistic Theory independently pointed out to us that adding an additive particle $k e$ before the indefinite article further increases the acceptability of these examples.
} 
b. O Petros exi mia dhaskala stin Veria, ke exi enan dhaskalo the Petros has a.F teacher.F in.the Veria and has one.M teacher.M stin Katerini. in.the Katerini 'Petros has a female teacher in Veria, and he has a male teacher in Katerini.'

In these contexts, nominal ellipsis with GENDER mismatch is actually possible. Specifically, Class I nouns are generally judged unacceptable under ellipsis with GENDER mismatch, as in the case of predicative nominals, but Class II nouns are acceptable (although as in the case of predicative nouns, the judgments do not seem to be completely stable)

a. *O Petros exi enan adherfo stin Veria, ke exi mia adherfi stin the Petros has a.m brother in.the Veria and has one.F (sister) in.the Katerini.

Katerini

(intended) 'Petros has a brother in Veria, and he has a sister in Katerini.'

b. *O Petros exi mia adherfi stin Veria, ke exi enan adherfo stin the Petros has a.F sister in.the Veria and has one.M(brother) in.the Katerini.

Katerini

(intended) 'Petros has a sister in Veria, and he has a sister in Katerini.'

(27) a. O Petros exi enan jatro stin Veria, ke exi mia jatro stin the Petros has a.M doctor in.the Veria and has one.F (doctor) in.the Katerini.

Katerini

'Petros has a male doctor in Veria, and he has a female doctor in Katerini.'

b. O Petros exi mia jatro stin Veria, ke exi enan jatro stin the Petros has a.F doctor in.the Veria and has one.M (doctor) in.the Katerini.

Katerini

'Petros has a female doctor in Veria, and he has a male doctor in Katerini.'

As the status of Class III nouns in this grammatical context are even less stable across speakers, as in the case of predicative nominals, we will not report their judgments here. But importantly, examples involving Class II nouns like (27), which receive more or less stable judgments, demonstrate that nominal ellipsis with GENDER mismatches in argument positions is actually possible, contrary to Merchant's (2014) claim.

Then, what makes Merchant's original data unacceptable? We argue that the culprit is the information structural properties of the examples that are naturally enforced by the polarity difference of the two conjuncts and the use of ala 'but'. In order to understand this, take the following examples with matching GENDER and without ellipsis. We use the negative concord determiners in these examples, as they sound significantly more natural in negative contexts.

(28) a. O Petros exi enan jatro stin Veria, ala dhen exi kanenan jatro the Petros has a.M doctor in.the Veria but not has no.m doctor stin Katerini. in.the Katerini

'Petros has a male doctor in Veria, but he doesn't have a doctor in Katerini.' 
b. O Petros exi mia jatro stin Veria, ala dhen exi kamia jatro stin the Petros has a.F doctor in.the Veria but not has no.F doctor in.the Katerini.

Katerini

'Petros has a female doctor in Veria, but he doesn't have a female doctor in Katerini.'

We observe that the most natural prosody of these sentences places a contrastive topic intonation on Veria and Katerini, and a focus intonation on enan/mia and kanenan/kamia (cf. Giannakidou \& Stavrou 1999). Importantly, such a contrastive intonation is not forced in the positive examples (23)-(25). It is beyond the scope of this paper to explain why the contrastive topic intonation is virtually obligatory in the negative examples but not in the positive examples, but we claim here that this information structural difference is the crucial factor that renders the former examples unacceptable. ${ }^{9}$

Firstly, a contrastive topic generally yields an 'exhaustive inference' that the asserted property (e.g. Petros has a female doctor in (28)) does not hold for all alternatives of the contrastively topicalised element (e.g. in Veria vs. in Katerini) (cf. Büring 1997; 2003; to appear). ${ }^{10}$ For instance, for the first conjunct of the acceptable example (28b) with a matching gender, the generated inference is that Petros has no female doctor in Katerini. This aligns with the assertion of the second conjunct, according to which Petros has no female doctor in Katerini. Similarly, the second conjunct of (28b) generates a contrastive inference that Petros has a female doctor in Veria, which is in line with the assertion in the first conjunct. Consequently the meanings of the two conjuncts align quite well in this case.

The same reasoning applies in (28a), where the two conjuncts match in MASCULINE, with one difference. There is an interpretive asymmetry between MASCULINE and FEMININE in Greek. Specifically, there are reasons to think that MASCULINE is actually semantically gender-neutral in Greek. In (28a), the exhaustive inference of the first conjunct is therefore gender-neutral. That is, it means that Petros has no doctor, male or female, in Katerini, rather than just that Petros has no male doctor in Katerini. Similarly, the second conjunct of (28a) generates an inference that Petros has no doctor, male or female, in Katerini, but he has one in an alternative place, i.e. Veria. Consequently the meanings of the two conjuncts align well in this case too.

Keeping this in mind, observe now that there is a contrast when different GENDERs are involved as in (29), which is identical to Merchant's original data in all relevant respects. This example is unacceptable with or without nominal ellipsis.

\section{*O Petros exi enan jatro stin Veria, ala dhen exi kamia jatro stin the Petros has a.M doctor in.the Veria but not has no.F doctor in.the Katerini. \\ Katerini \\ (intended) 'Petros has a male doctor in Veria, but he doesn't have a female doc- tor in Katerini.'}

\footnotetext{
${ }^{9}$ An anonymous reviewer for Natural Language and Linguistic Theory remarks that (20)-(22) are acceptable to them. We did not replicate their judgments with our informants, but we would like to note that our prediction here is that if different prosodies (perhaps together with certain specific contexts) were available to a speaker, they might alter the essential pragmatic properties of the examples (i.e. their exhaustive inferences) and make them acceptable, and also that ellipsis might play a role in determining which prosodies are available (or more natural). While we leave this as a theoretical possibility here, we will discuss related points below.

10 There is one more exhaustive inference to the effect that the focus alternatives of the asserted property do not hold of the contrastive topic, e.g. for the acceptable example in (28a), Petros only has one doctor who is male in Veria, which could be a pragmatic inference. This inference is not crucial here.
} 
We claim that (29) is unacceptable for the following reasons. The FEMININE noun in the second conjunct gives rise to the inference that Petros has no female doctor in Katerini but he has one in Veria (we will discuss this in more detail in Section 5.1). Notice that the exhaustive inference of the first conjunct says that Petros has no doctor, male or female, in Katerini, but the second sentence only asserts that he has no female doctor, despite the fact that the assertion could be stronger, i.e. that he has no doctors, male or female, in Katerini. It is reasonable to assume that such a sentence causes infelicity. In fact, a similar constraint can be independently observed with examples that do not even involve nouns with GENDER, such as (30).

(30) ??In Veria ${ }_{C T}$, John has a relative. In Katerini ${ }_{C T}$, he has no cousin.

As in the Greek example above, the exhaustive inference of the first conjunct here is stronger than what is asserted in the second sentence, and the sentence is infelicitous. Compare this to the following acceptable sentence, where the second sentence asserts something as strong as or stronger than the exhaustive inference of the first conjunct.

In Veria $_{C T}$, John has a cousin. In Katerini ${ }_{C T}$, he has no cousin/relative.

This analysis makes one testable prediction: When the noun in the positive sentence is changed to FEMININE and the noun in the negative sentence changed to MASCULINE, (29) should become as felicitous as (31), because the second sentence will assert something stronger than the exhaustive inference of the first sentence. This prediction is borne out, as shown in (32). ${ }^{11}$ This example is acceptable with or without ellipsis.

O Petros exi mia jatro stin Veria, ala dhen exi kanenan jatro stin the Petros has a.F doctor in.the Veria but not has no.m doctor in.the Katerini.

Katerini

(intended) 'Petros has a female doctor in Veria, but he doesn't have a doctor in Katerini.'

Similarly, the following example without an entailment between the assertions and exhaustive inferences is perfectly acceptable with or without ellipsis.

\author{
O Petros exi enan xazo jatro stin Veria, ala mia ekspipni jatro \\ the Petros has a.M stupid.m doctor in.the Veria but a.F smart.F (doctor) \\ stin Katerini. \\ in.the Katerini \\ 'Petros has a stupid doctor in Veria, but a smart female one in Katerini.'
}

We therefore conclude that the unacceptability of (29) can be attributed to the pragmatics of contrastive topic. ${ }^{12}$

\footnotetext{
${ }^{11}$ In an earlier version of the paper, we reported that (32) was also unacceptable. We rechecked the data with five native speakers. Four of them judged (32) as acceptable and (29) as not, and the one remaining speaker reported a mild contrast in the same direction. We thank an anonymous reviewer for Natural Language and Linguistic Theory for sharing their judgments, as well as pointing out that this data point supports our theory, as explained below.

${ }^{12}$ We would like to mention here another analytical possibility to account for the infelicity of (29). We observe that the first sentence of (29) tends to be associated with an exhaustive inference that Peter only has one doctor in Veria, who is male. Notice that due to the contrastive topic on stin Katerini 'in Katerini' in the second sentence, it is associated with the inference that somewhere other than Katerini, he has a
} 


\section{Merchant's theory}

To summarize the key observations so far, we have presented new evidence for Merchant's (2014) classification of noun pairs with interpreted GENDER that involves focus constructions, and counterexamples against his claim about the predicative vs. argument asymmetry. Merchant (2014) puts forward an analysis that derives the putative predicative vs. argument contrast, so it simply cannot be maintained in its full form. Nonetheless we will closely review how it works here, as the alternative theory we will propose in the next section shares certain insights with his analysis.

One of the key ingredients in Merchant's analysis that derives the (false) predicative vs. argument contrast is that there are two separate strategies available in Greek that lead to missing nouns on the surface: (i) PF-Deletion of $\mathrm{nP}$ triggered by the ellipsis feature [E]; and (ii) a null proform $e_{N}$. He also crucially assumes that the PF-Deletion strategy is only available under total identity between the antecedent and the ellipsis site, and therefore is never employed with mismatching GENDER, and the null proform $e_{N}$, on the other hand, is used to account for such cases.

Specifically, Merchant assumes that GENDER features in the nominal domain occupy a syntactic position above NP, as illustrated in (34).
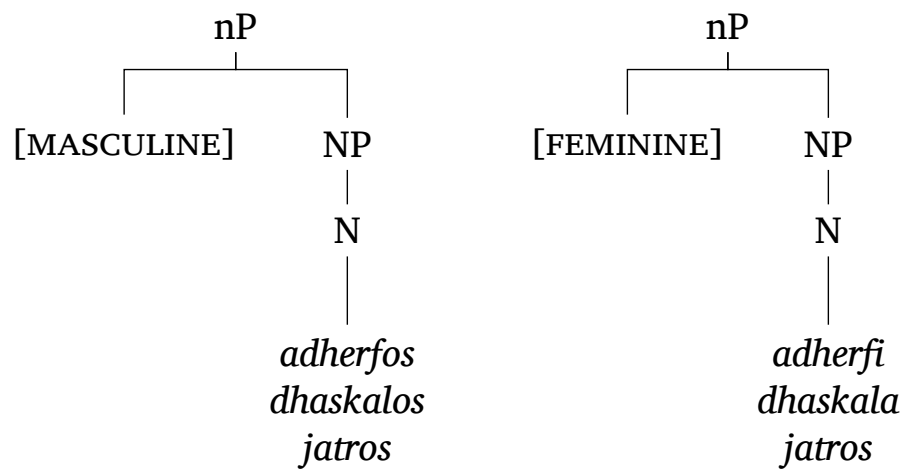

By assumption, these GENDER features have presuppositional meanings, as in (35).

$$
\begin{array}{ll}
\text { a. } & \llbracket[\text { MASCULINE }] \rrbracket=\lambda P_{e t} \lambda x_{e}: \operatorname{male}(x) \cdot P(x) \\
\text { b. } & \llbracket[\mathrm{FEMININE}] \rrbracket=\lambda P_{e t} \lambda x_{e}: \operatorname{female}(x) \cdot P(x)
\end{array}
$$

Merchant furthermore assumes that some nouns carry gender presuppositions, while others have none. More precisely, the denotations of the three classes of GENDERed nouns look like the following. Note importantly that all gender inferences are presuppositional here.

\section{Class I}

a. $\llbracket$ adherfos $\rrbracket=\lambda x_{e}: \operatorname{male}(x) \cdot \operatorname{sibling}(x)$

b. $\quad \llbracket$ adherfi $\rrbracket=\lambda x_{e}:$ female $(x) \cdot \operatorname{sibling}(x)$

\section{Class II}

$$
\llbracket j a t r o s \rrbracket=\lambda x_{e} \cdot \operatorname{doctor}(x)
$$

\footnotetext{
female doctor. Since in this mini-discourse the only other salient location is Veria, one could interpret this inference as saying that he has a female doctor in Veria. Then, this contradicts what the first sentence states under the exhaustive inference. Although the relevant readings of the two conjuncts seem to be possible at least for (29) in an out-of-the-blue context, they are not the only interpretive possibilities.
} 
Class III

a. 【dhaskalos $\rrbracket=\lambda x_{e}$.teacher $(x)$

b. $\llbracket$ dhaskala $\rrbracket=\lambda x_{e}$ : female $(x)$. teacher $(x)$

With this semantics, Merchant goes on to claim that the difference in the presence/absence of a gender presupposition as shown here makes certain cases of ellipsis with GENDER mismatch ungrammatical. Let us go through the two strategies for nominal ellipsis in turn to see how his analysis works.

Firstly, PF-deletion triggered by [E] accounts for nominal ellipses with matching GENDER. Merchant assumes that [E] appears on Num and requires total semantic identity between the antecedent $\mathrm{nP}$ and elided nP. Concretely, with the following DPs, the second $\mathrm{nP}$ (highlighted by a dotted square) can be elided in reference to the completely identical antecedent $\mathrm{nP}$ (also in a dotted square).

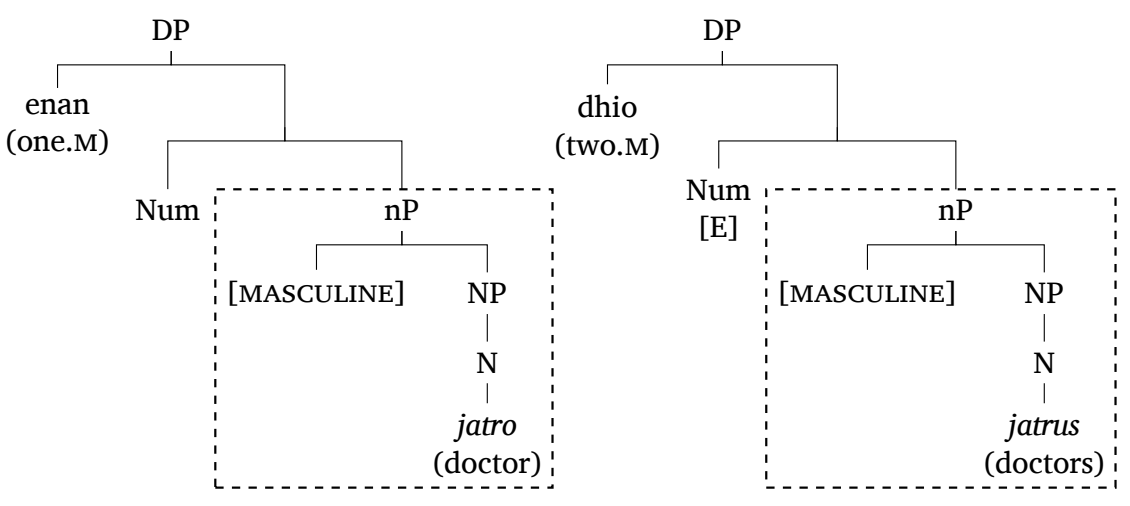

With a mismatch in GENDER, however, the presupposition triggered by the GENDER feature of the elided $n \mathrm{P}$ will disrupt ellipsis licensing, as Merchant assumes ellipsis to be only possible under complete identity, including the presuppositions. ${ }^{13}$ Consequently, the PF Deletion strategy cannot be employed when there is a GENDER mismatch.

On the other hand, the second strategy employing the pro-form $e_{N}$ can sometimes be used to give rise to ellipsis with GENDER mismatch. Merchant assumes that $e_{N}$ is selected for by Num and refers to a contextually salient property denoted by some other noun in the prior discourse. These assumptions are meant to account for the asymmetric licensing with nouns like dhaskalos-dhaskala. The relevant example is repeated here (the judgments here are as reported in Merchant 2014).

a. O Petros ine kalos dhaskalos, ala i Maria ine mia kakia the Petros is good.M teacher.M but the Maria is a.F bad.F thaskala.

(teacher.F)

'Petros is a good teacher, but Maria is a bad one.'

b. *I Maria ine kali dhaskala, ala o Petros ine enas kakos the Maria is good.F teacher.F but the Petros is a.M bad.M dhaskalos.

(teacher.M)

(intended) 'Maria is a good teacher, but Petros is a bad one.'

\footnotetext{
${ }^{13}$ One might contest this assumption on the grounds that mismatches in gender presuppositions and other presuppositions triggered by $\varphi$-features (or ' $\varphi$-presuppositions' as we call them here) are generally tolerated under ellipsis (Ross 1967; Fiengo \& May 1994; Johnson 2014). We will come back to this in Section 4.1 below.
} 
In this example, $e_{N}$ is resolved to the MASCULINE antecedent dhaskalos 'teacher', which crucially has no presupposition of its own, although the MASCULINE feature, which sits above the noun, triggers a gender presupposition. Consequently, resolving $e_{N}$ to the MASCULINE noun will not cause a semantic problem in the second conjunct, even though the subject there is FEMININE. By contrast, in the case of (5b), $e_{N}$ is resolved to the FEMININE noun dhaskala 'teacher', which by assumption has a gender presupposition in its semantics, and thus causes a semantic clash with a MASCULINE subject. Hence the asymmetric licensing.

Furthermore, Merchant explains the (im)possibility of using $e_{N}$ to achieve nominal ellipsis with GENDER mismatch for the other two classes of nouns as well. For EPICENE nouns, $e_{N}$ can be employed with GENDER mismatch in either direction, since these nouns do not have gender presuppositions and $e_{N}$ in the second conjunction will be compatible with a subject of either gender. By contrast, nouns like adherfos-adherfi have gender presuppositions, and $e_{N}$ with GENDER mismatch always results in semantic anomaly.

Finally, Merchant derives the putative impossibility of nominal ellipsis in argument positions as follows. He assumes that the GENDER features that appear on D and A in examples like (5a) come from the subject of the predicational sentence, as depicted in the following tree diagram.

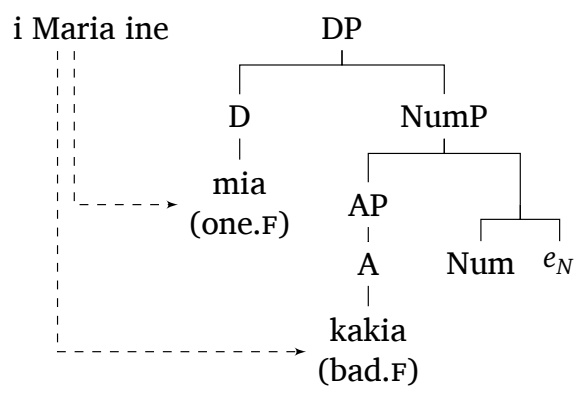

In argument positions, however, D and A will not be able to obtain $\varphi$-features, which by assumption results in ungrammaticality. Merchant furthermore assumes $e_{N}$ needs to be in a certain local relation with $\mathrm{D}$ for syntactic reasons, and therefore at least D must be present whenever $e_{N}$ is. As a result, nominal ellipsis with a GENDER mismatch is never possible in argument positions.

\subsection{Assessment}

To summarize, the following are crucial ingredients of Merchant's (2014) proposal.

i. There are two strategies for nominal ellipsis, (i) PF-deletion and (ii) a pro-form $e_{N^{*}}$

ii. PF-deletion requires total semantic identity, including the presupposition. This bans all cases of deletion involving GENDER mismatch.

iii. The proform $e_{N}$ needs to be licensed by a local D. When $e_{N}$ is in argument position, the $\varphi$-features of D will not be valued, which results in ungrammaticality.

iv. Some nouns have gender presuppositions in their lexical semantics (i.e. Class I nouns and Class III FEMININE nouns), while others (Class II nouns and Class III MASCULINE nouns) don't.

Given our observation from the previous section that nominal ellipsis with GENDER mismatch is actually possible in predicative and argument positions, Merchant's (2014) analysis cannot be retained in its full form. However, there is a very easy fix that makes it 
compatible with nominal ellipsis with GENDER mismatches in argument position, namely, simply by dropping 3. above. That is, it could be assumed that $\varphi$-features on determiners and adjectives need not be syntactically licensed and are simply interpreted (or licensed by a $\varphi$-head above the DP; Sauerland 2003; see Section 5.2.2 below for a concrete implementation). With this fix, nominal ellipsis with GENDER mismatch becomes possible in both predicative and argument positions under his theory.

However, there are remaining issues. Firstly, there is now no reason to postulate two separate mechanisms for nominal ellipsis in Greek. Rather, we will demonstrate below that all the relevant data can be accounted for just with PF-deletion (we will also discuss and reject the alternative possibility of only using $e_{N}$ in Section 6.3). Thus, we will drop Merchant's (2014) assumptions 1. and 3. above.

Notice that in order for this alternative theory to work, we will also have to drop 2. above, according to which deletion requires complete semantic identity, because that is what prevents deletion from applying for ellipsis with GENDER mismatch. As we will see immediately below, there is actually independent reason to think that ellipsis (and focus constructions) systematically ignore presuppositions triggered by $\varphi$-features (' $\varphi$-presuppositions') including GENDER features, and ellipsis involving such mismatches in $\varphi$-features are generally licit (Ross 1967; Fiengo \& May 1994; Spathas 2010; Johnson 2014). For instance, the following examples involving ellipsis with GENDER mismatches are all grammatical in English.
a. NP ellipsis:
Mary's story about her family is funny, but John's story of his family is not.
b. VP ellipsis:
Mary likes her relatives, but John doesn't like his relatives.
c. TP ellipsis/sluicing:
Mary remembers when she came to the UK (but not how), while John re- members how heame the UK (but not when).

In other words, Merchant's assumption 2. can be shown to be problematic on independent grounds.

This leaves us with 4. about the distinction between nouns with and without gender presuppositions. While we adopt this idea to make sense of the three classes of noun pairs in Greek, we also claim that it needs to be revised to account for the data involving focus constructions discussed in Section 2.2. In particular, recall that for Merchant, gender inferences are all presuppositional. However, it is widely observed that focus alternatives are generally oblivious to $\varphi$-presuppositions, including gender presuppositions, just like structures under ellipsis (see Spathas 2010; Jacobson 2012; Sauerland 2013 for relevant discussion).$^{14}$ For instance, consider the following examples, under the bound readings of the possessive pronouns.

(42) a. Of all the students, only I did my homework.

b. Of all the students, only John did his homework.

c. Of all the students, only Mary did her homework.

\footnotetext{
${ }^{14}$ There is some controversy in the literature regarding the analysis of examples like (42). In particular, one popular analysis says that the $\varphi$-features on these pronouns are semantically uninterpreted and are morphological reflections of the agreement relation with the binder (Heim 2008; Kratzer 1998; 2009), but there are other ideas as well (Spathas 2010; Jacobson 2012; Sauerland 2013; Sudo 2012; 2014a). For the most part, we can be neutral with respect to this debate, but for certain data points, e.g. (73), the agreement-based theory has nothing to say, as there is nothing that agrees with the GENDER marking (see Spathas 2010 and Sudo 2012; 2014a for similar arguments against the agreement-based theory).
} 
Suppose that the relevant students are the speaker, John and Mary. Then, (42a) entails that Mary and John didn't do their homework, (42b) that the speaker and Mary didn't do their homework, and (42c) that the speaker and John didn't do their homework. What is of importance here is that the $\varphi$-features (person and GENDER features here) of the bound possessive pronoun seem to have no semantic effects in the focus alternatives. For instance, what is negated in (42c) looks like the following, and the third person and FEMININE features do not figure here.

a. I did my homework.

b. John did his homework.

On the other hand, assertions are never ignored. For instance, (44) does not entail that John is not an athlete, but only that John is not a female athlete.

Of all the students, only Mary is a female athlete.

If all gender inferences of Greek nouns with gender inferences are presuppositional, the data like (9) and (11), repeated below, will remain puzzling.

a. Mono o Petros ine adherfos tu Jani. only the Petros is sibling.M the.GEN Janis.GEN

'Only Petros is a brother of Janis'.'

$\nRightarrow$ Maria is not Janis's sister

b. Mono i Maria ine adherfi tu Jani. only the Maria is sibling.F the.GEN Janis.GEN 'Only Maria is a sister of Janis'.' $\nRightarrow$ Petros is not Janis's brother

(11) a. Mono o Petros ine dhaskalos. only the Petros is teacher.M 'Only Petros is a teacher.'

$\Longrightarrow$ Maria is not a teacher

b. Mono i Maria ine dhaskala. only the Maria is teacher.F 'Only Maria is a teacher.'

$\nRightarrow$ Petros is not a teacher

That is, the gender inferences in the focus alternatives here should be ignored, and consequently, (9a), (9b) and (11b) are expected to have entailments about the opposite gender as well, just like (11a) (and also (10) with Class II nouns).

In order to account for this, we will claim that Class I nouns like aderfos and aderfi and Class III FEMININE nouns like dhaskala have gender inferences in both assertion and presupposition, while Class II nouns like jatros and Class III MASCULINE nouns have no gender inferences in either dimensions of meaning. Furthermore, when showing FEMININE agreement, jatros has a gender inference only as a presupposition, and when showing MASCULINE agreement, it receives a gender inference in competition with the FEMININE version of the noun. We will raise evidence for this analysis and give a more detailed explanation about how this accounts for the above data in the next section.

\subsection{Merchant's argument from extraction}

Before leaving this section, we should mention Merchant's (2014) data involving extraction from the ellipsis site, which he raises as support for his postulation of the proform $e_{N^{*}}$. He observes that extraction from the ellipsis site is with matching GENDER, but not 
with mismatching GENDER. ${ }^{15}$ Here, what is extracted is the genitive phrase, and dhikigoro 'lawyer' is an EPICENE noun.

a. Tu Jani, tha dho ton $\operatorname{xazo}_{F}$ dhikigoro $t . \mathrm{Tu}$ the.GEN Janis.GEN will see.I the.M stupid.M lawyer $t$. the.GEN Kosta, tha dho ton ekspipno ${ }_{F}$ dhikigorot. Kostas, will see.I the.M smart.M (lawyer $t$ ) 'I'll see Janis' stupid (male) lawyer, and I'll see Kostas' smart one.'

b. ??Tu Jani, tha dho ton $\mathrm{xazo}_{F}$ dhikigoro $t$. $\mathrm{Tu}$ the.GEN Janis.GEN will see.I the.M stupid.M lawyer $t$. the.GEN

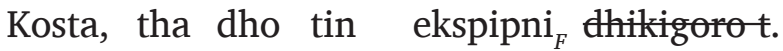
Kostas, will see.I the.F smart.F (lawyer $t$ ) 'I'll see Janis' stupid male lawyer, and I'll see Kostas' smart female one.'

Merchant argues that this observation speaks in favor of his analysis for the following reason. Recall that according to him, GENDER-matching ellipsis can be derived via PF deletion, while GENDER-mismatching ellipsis always involves a null pronominal $e_{N^{*}}$ It is then expected that extraction in the latter case should be impossible, given that extraction from a pronominal should be generally banned (cf. Fiengo \& May 1994; Schwarz 2000; Johnson 2001; Saab to appear). The above contrast in fact accords well with this prediction.

While the observation seems to be solid, we would like to disagree with the conclusions Merchant draws. Firstly, the unacceptability of (45b) is actually not as grave as one might expect for a violation of the ban on extraction from a pronominal element. In fact, the contrast appears to be comparable to the mere degradation associated with ellipses with GENDER mismatches across the board. Secondly, we observe that the baseline cases without ellipsis already exhibit the same kind of contrast (at least for some speakers): ${ }^{16}$

a. $\mathrm{Tu}$ Jani, tha dho ton $\mathrm{xazo}_{F}$ dhikigoro. $\mathrm{Tu}$ Kosta, the.GEN Janis.GEN will see.I the.M stupid.m lawyer. the.GEN Kostas, tha dho ton ekspipno $_{F}$ dhikigoro. will see.I the.M smart.m lawyer 'I'll see Janis' stupid (male) lawyer, and I'll see Kostas' smart one.'

\footnotetext{
${ }^{15}$ Merchant's examples are reproduced in (i) (his (43) and (47)). He marks the second sentence with a *, but as we observe here, the contrast is not as sharp as Merchant's notation might suggest.
}

(i) Tis istorias idha ton palio [proedhro $t$ ], kai...

the history.GEN I.saw the.M old.M [chair.m $t$ ], and

'I saw the former chairperson (masc) of the history department, and..

a. tis glossologias tha dho ton kenurio.

the linguistics.GEN fut I.see the.M new.M

(lit.) 'of linguistics, I'll see the new (masc) (one).'

b. "tis glossologias tha dho tin kenuria.

the linguistics.GEN fut I.see the.F new.F

(lit.) 'of linguistics, I'll see the new (fem) (one).'

What is extracted here is probably a complement PP, while it is a possessor in (45), but this difference does not seem to matter for judgments.

${ }^{16}$ Three out of our six informants report a slight improvement for (46b) over (45b), but even for them the contrast is not at all sharp. 
b. ??Tu Jani, tha dho ton $\mathrm{xazo}_{F}$ dhikigoro. $\mathrm{Tu}$ Kosta, the.GEN Janis.GEN will see.I the.M stupid.M lawyer. the.GEN Kostas, tha dho tin ekspipni ${ }_{F}$ dhikigoro. will see.I the.F smart.F lawyer 'I'll see Janis' stupid male lawyer, and I'll see Kostas' smart female one.'

Although we need to leave an analysis of these data for another occasion, they indicate that whatever is responsible for the contrast is not the mechanism of ellipsis, contrary to what Merchant (2014) assumes. Rather, ellipses with matching GENDER and non-matching GENDER seem to show mild contrasts across the board (cf. fn.4). The nature of these contrasts are not very clear to us at this moment, but that they are not very sharp suggests that they are likely to be caused by non-syntactic factors, and given that they are observed with the overt versions of the sentences, they have little, if any, to do with ellipsis per se. ${ }^{17}$

\section{Interpretation of GENDER}

In this section, we will spell out an improved analysis of nouns with interpreted GENDER in Greek and show how it accounts for the main data we have seen above, as well as additional data. As discussed above, the only crucial aspect of Merchant's (2014) theory we are adopting is the distinction between nouns with and without gender in their semantics. In order to account for the behavior of such nouns in focus constructions, we propose that gender inferences can be purely presuppositional or also in the assertive dimension of the meaning (cf. Percus 2011). ${ }^{18}$

Let us look at some concrete examples. We analyze Class I nouns like adherfos and adherfi as having gender inferences in both presuppositional and assertive dimensions of meaning. ${ }^{19}$

\footnotetext{
${ }^{17}$ We furthermore observe that for two out of six speakers we consulted with, extraction from an indefinite phrase is perfectly acceptable, even with a GENDER-mismatch ellipsis.
}

(i) a. Tu Jani, tha dho ton $\mathrm{xazo}_{F}$ dhikigoro. $\mathrm{Tu}$ Kosta, tha dho enan the.GEN Janis.GEN will see.I the.M stupid. lawyer. the.GEN Kostas, will see.I a.M ekspipno $_{F}$ thikigore. smart.M lawyer 'I'll see a stupid (male) lawyer of Janis', and I'll see a smart one of Kostas'.'

b. $\mathrm{Tu}$ Jani, tha dho ton $\mathrm{xazo}_{F}$ dhikigoro. Tu Kosta, tha dho mia the.GEN Janis.GEN will see.I the.M stupid. lawyer. the.GEN Kostas, will see.I a.F ekspipni ${ }_{F}$ dhikigore. smart.F lawyer 'I'll see a stupid male lawyer of Janis', and I'll see a smart female one of Kostas'.'

Again, we cannot offer an explanation of the definite-indefinite contrast here, but the lack of a contrast in (i) for the relevant speakers indicates that at least for these speakers, extraction from ellipsis with GENDER mismatches is not impossible, which is problematic for Merchant.

${ }^{18}$ Note that this does not necessarily mean that the assertion is redundant, because the assertion can be stronger than the presupposition. Also, other cases of having the same inference in the presupposition and assertion can be found elsewhere, e.g. quit smoking presupposes that the subject used to smoke and asserts that they used to smoke but do not anymore (Abrusán 2011; Sudo 2012). In fact, theories of the triggering problem of (soft) presuppositions commonly assume that certain parts of the assertive meaning become presuppositions.

${ }^{19}$ For MASCULINE nouns like adherfos 'male sibling', the observations in this paper are actually consistent with the analytical possibility that their gender presupposition is semantically null, just as in the case of MASCULINE nouns with purely presuppositional gender inferences. However, the infelicity of sentences like (i) suggests that this possibility is not on the right track. That is, (i) is not simply false, and more adequately described as presupposition failure (cf. 'Mary is not a male sibling of Janis's', which is not infelicitous but false).

(i) *I Maria ine adherfos tu Jani. the Maria is sibling.M the.GEN Janis.GEN 'Maria is a brother of Janis's.' 
a. $\llbracket$ adherfos $\rrbracket=\lambda x$ : male $(x) \cdot \operatorname{male}(x) \wedge \operatorname{sibling}(x)$

b. $\quad \llbracket$ adherfi $\rrbracket=\lambda x_{e}:$ female $(x)$. female $(x) \wedge \operatorname{sibling}(x)$

For Class II nouns, the EPICENE nouns, we adopt Merchant's (2014) idea that they have no lexical specification for gender, although they can get a gender inference in some other way, as we will see.

$$
\llbracket j a t r o s \rrbracket=\lambda x_{e} \cdot \operatorname{doctor}(x)
$$

The MASCULINE and FEMININE nouns in Class III are, on the other hand, not symmetric, and their denotations look like (49).

$$
\begin{aligned}
& \text { a. } \text { 【dhaskalos } \rrbracket=\lambda x_{e} \cdot \operatorname{teacher}(x) \\
& \text { b. } \llbracket \text { dhaskala }=\lambda x_{e}: \operatorname{female}(x) \cdot \operatorname{female}(x) \wedge \operatorname{teacher}(x)
\end{aligned}
$$

This looks very close to Merchant's(2014) analysis but we will show that by combining it with the idea of semantic markedness and gender competition, we can make sense of our observations about focus constructions.

\subsection{Unmarked GENDER and gender competition}

For Merchant's (2014), [MASCULINE] and [FEMININE] are symmetric at least in the semantics in the sense that both features give rise to gender presuppositions. However, since Roman Jakobson's seminal work (Jakobson 1984), it is well recognized that GENDERs in natural languages are often not equal. And as far as human-denoting nouns in Greek are concerned, [MASCULINE] is less marked than [FEMININE] in the semantic sense, i.e. [MASCULINE] can often be used in a gender-neutral manner as an 'elsewhere GENDER', so to speak (see Spathas 2010 for Greek and Corbett 1991; Bobaljik \& Zocca 2011; Heim 2008; Kramer 2015; Percus 2006; 2011; Sauerland 2008b for other languages). ${ }^{20}$ This is most clearly observed with items that have gender inferences in the domain of presupposition, e.g. pronouns.

There are independent reasons to believe that interpreted GENDERs (and possibly other interpretable $\varphi$-features) on pronouns are presupposition triggers (Cooper 1983; Heim \& Kratzer 1998; Kratzer 1998; 2009; Heim 2008; Jacobson 2012; Sudo 2012). In English, for example, her is used to refer to a female individual, and if it is used to refer to a male individual, it gives rise to presupposition failure. More specifically, assuming that pronouns denote variables, Heim \& Kratzer (1998) propose the following treatment, based on Cooper (1983) (see Spathas 2010 for Greek pronouns). ${ }^{21}$

(50) For any index $i$ and assignment $g$,

a. $\quad\left\ulcorner\right.$ her ${ }_{i} \in \operatorname{dom}\left(\llbracket \mathbb{I} \rrbracket^{g}\right)$ iff $g(i)$ is female.

b. Whenever $\left\ulcorner\operatorname{her}_{i}\right\urcorner \in \operatorname{dom}\left(\llbracket \mathbb{I} \rrbracket^{g}\right)$, $\llbracket$ her $_{i} \rrbracket^{g}=g(i)$.

Also, by keeping the non-trivial gender presupposition in the denotation of adherfos, we can maintain the uniformity of the interpretation of GENDER features on nouns: if a noun has a gender inference, it both presupposes and asserts it, and if not, it is simply unmarked at the nominal level.

20 Jakobson's notion of 'unmarked GENDER', which has been used by many subsequent authors (cf. Bobaljik \& Zocca 2011; Kramer 2015), is related but not exactly the same as the notion of semantic unmarkedness, which is what we are after here. In Greek, semantic markedness does not seem to correlate necessarily with morphological markedness. We thank an anonymous reviewer for Natural Language and Linguistic Theory for drawing our attention to Roman Jakobson's work.

${ }^{21}$ We are not committed to a particular analysis of pronouns in the present paper. See Jacobson (2012) for a treatment of gender presuppositions on pronouns in variable-free semantics. It should also be mentioned that Cooper (1983) distinguishes the semantic contributions of GENDER features on free and bound pronouns. 
One might be tempted to give a similar analysis to MASCULINE pronouns, but unlike FEMININE pronouns, MASCULINE pronouns in Greek can be used as gender-neutral pronouns. ${ }^{22}$ This asymmetry between MASCULINE and FEMININE can be observed, for example, when the pronoun is bound by a quantifier with individuals of both genders in the domain of quantification. In such contexts, a MASCULINE pronoun is felicitous but not a FEMININE pronoun, as shown in (51). Here, the intended reading is one where the pronoun tu/tis is bound by the disjunctive subject.
a. Kapios fititis i kapia fititria evapse to domatio tu. some.M student.M or some.F student.F painted the room his 'Some male student or some female student painted his room.'
b. \#Kapios fititis i kapia fititria evapse to domatio tis. some.M student.M or some.F student.F painted the room her 'Some male student or some female student painted her room.'

As we will explain more precisely below, the unacceptability of (51b) shows that FEMININE pronouns are exclusively used for FEMININE referents (see the references cited above for similar facts in other languages). We will present below further evidence of the gender-neutrality of MASCULINE in Greek with data involving gender features on determiners and adjectives (namely, (64), (65), (68) and (69); see also Spathas 2010).

In sentences like (51), MASCULINE pronouns behave like gender-neutral pronouns, but in other contexts, they are not completely void of gender inferences. For instance, a free MASCULINE pronoun is typically used to refer to a male individual, and it is simply infelicitous to use it to refer to, say, Hilary Clinton, while knowing her gender. Concretely, (52) cannot be used to mean 'I voted for Hilary Clinton'.
Ton psifisa.
him voted.I
'I voted for him.'

Also, the following example is unacceptable under the bound reading of $t u$.
Kapia fititria evapse to domatio tu.
some.F student.F painted the room his
'Some female student painted his room.'

To reconcile these facts with gender-neutral uses, we follow Percus (2006; 2010; 2011) and Sauerland (2008a; b) and assume that [MASCULINE] is actually semantically completely gender-neutral in languages like Greek, but systematically excluded when [FEMININE] could be used felicitously instead. In order to make this idea more concrete, we postulate a principle forcing the use of the more specific form of the MASCULINE and FEMININE pair, whenever possible (cf. the literature on anti-presupposition/implicated presupposition, e.g. Heim 2008; Percus 2006; 2011; Sauerland 2003; 2008a; b). ${ }^{23}$

\footnotetext{
${ }^{22}$ The corresponding data in English are more complicated. See discussion in Corbett (1991: Ch.7) and McConnell-Ginet (2011), for example.

${ }^{23}$ The authors cited here, except for Percus (2011), formulate the principle as a general principle about alternative expressions that have presuppositions of different strengths, which is often called Maximize Presupposition (MP) after Heim (1991). As it turns out, we cannot use MP, as formulated in Heim (1991), but in the current literature its formulation is actively debated, and also the principle is sometimes given different names (see Spector \& Sudo 2017; Marty 2017; Anvari 2019, for example). Among these, we could use Spector \& Sudo's (2017) formulation, but in order to avoid unnecessary discussion on how they motivate their principle, we will use the version of the principle that is specific to gender.
} 
If $S$ has an alternative $S^{\prime}$ that only differs in the GENDER feature on some item, $\alpha$ vs. $\alpha^{\prime}$, respectively, then, the use of $S$ in context $c$ is infelicitous if all of the following are true.

a. $\quad \alpha^{\prime}$ asymmetrically entails $\alpha$ in the presupposition and/or assertion. ${ }^{24}$

b. The presupposition of $\alpha^{\prime}$ is satisfied in $c$; and

c. The assertions of $S$ and $S^{\prime}$ are equivalent.

The Principle of Gender Competition accounts for the data in (51) as follows. By assumption, the FEMININE pronoun tis presupposes that the referent is female. In (51b), this presupposition makes one of the disjunctive possibilities unable to be true. Generally, a disjunction is only felicitous if all the disjuncts are possibly true (Gazdar 1979). Since this is not the case for (51b), the example is unacceptable. On the other hand, the MASCULINE pronoun in (51a) has no presupposition by assumption. The Principle of Gender Competition says that (51a) is only felicitous in contexts where (51b) is not felicitous. Since (51b) is infelicitous everywhere, (51a) can be used in any context.

In cases where the FEMININE counterpart could be used felicitously, on the other hand, a MASCULINE pronoun ceases to be gender-neutral, as predicted by the Principle of Gender Competition. Suppose that we know that Hilary Clinton is female. Then, in order to refer to her, the use of a FEMININE pronoun is forced by the Principle of Gender Competition, and the use of the MASCULINE pronoun is consequently banned, although it is semantically coherent. The example in (53) is explained similarly: In this sentence, the FEMININE pronoun tis could be felicitously used instead, which blocks the use of the MASCULINE pronoun tu.

\subsection{Technical remarks}

At this point, we would like to digress a bit and remark on some technical details.

\subsubsection{Gender competition and local contexts}

Firstly, the Principle of Gender Competition is meant to apply at every local level, not just at the top-most level of the sentence. In order to see why this is necessary, consider the following examples. The intended interpretation is the one where the possessive pronouns refer to Maria.
a. *I Maria evapse to domatio tu. the.F Maria painted the room his
b. I Maria evapse to domatio tis. the.F Maria painted the room her 'Maria painted her room.'

At the level of the whole sentence, (55a) has the exact same presupposition and assertion as (55b). That is, although the MASCULINE pronoun tu has no gender presupposition of its own, the subject DP is associated with a gender presupposition (which is visible on the FEMININE definite determiner $i$; see Section 5.3 for more discussion on determiners). If the Principle of Gender Competition only applied at the sentential level, (55b) would fail to be stronger than (55a), thereby making the application of the principle vacuous.

In order to correctly rule out the example in (55a), we adopt Singh's (2011) idea and assume that the Principle of Gender Competition is checked at every local context (in the sense of Heim 1982; 1983; Schlenker 2009, among others). We will not technically define local contexts here, as it requires dynamicization of the entire semantic system, which 
is routine but significantly complicates the exposition (see Singh 2011 for a concrete formulation for a similar principle Maximize Presupposition). Yet, the idea should be easy to grasp: (55a) violates the Principle of Gender Competition at levels below the subject, since at these levels (55b) has a stronger presupposition due to the gender presupposition on the possessive pronoun, which is satisfied here.

Similarly, the following examples require local computation of the principle. ${ }^{24}$
a. *I Maria ine kalos jatros.
the Maria is good.M doctor
b. *I Maria ine (kalos) dhaskalos.
the Maria is (good.M) teacher.M

Although these examples are semantically coherent, they are made unacceptable due to the felicity of the following alternatives.
a. I Maria ine kali jatros.
the Maria is good.F doctor
'Maria is a good doctor.'
b. I Maria ine (kali) dhaskala.
the Maria is (good.F) teacher.F
'Maria is a (good) teacher.'

Thus, local computation of the principle is ultimately necessary, but the technical details are omitted here for the sake of brevity.

\subsubsection{GENDER on determiners and adjectives}

Secondly, we would like to comment on other exponents of GENDER than nouns, such as determiners and adjectives. We could assume one of two things here, and we leave the choice open. One possibility is to analyze their GENDER features as presuppositional, as in (58) and (59). For expository purposes, let us assume indefinite articles denote existential determiners, and adjectives function as intersective modifiers, but nothing crucial hinges on this. We also ignore number features. ${ }^{25}$

$$
\begin{aligned}
& \text { a. } \llbracket \text { enan } \rrbracket=\lambda \mathrm{P}_{\langle e, t\rangle} \cdot \lambda Q_{\langle e, t\rangle} \cdot \exists x(P(x) \wedge Q(x)) \\
& \text { b. } \llbracket \operatorname{mia} \rrbracket=\lambda P_{\langle e, t\rangle} \cdot \lambda Q_{\langle e, t\rangle}: \forall x(P(x) \rightarrow \text { female }(x)) . \exists x(P(x) \wedge Q(x)) \\
& \text { a. } \llbracket \text { kalos } \rrbracket=\lambda x_{e} \cdot \operatorname{good}(x) \\
& \text { b. } \llbracket \text { kali } \rrbracket=\lambda x_{e}: \operatorname{female}(x) \cdot \operatorname{good}(x)
\end{aligned}
$$

Due to the Principle of Gender Competition, which needs to apply at every level, all exponents need to have the same GENDER, which is a good consequence in the case of Greek. ${ }^{26}$ Another possibility is to assume that there is a semantically interpretable occurrence of the GENDER feature outside of DP, which syntactically agrees with the uninterpretable

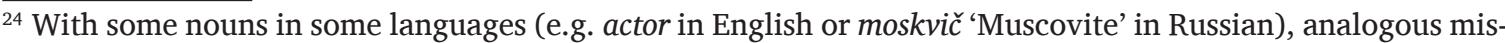
matches are tolerated, at least for some speakers (cf. Bobaljik \& Zocca 2011). Also, some animal-denoting nouns in Greek have similar properties, which we will discuss in Section 6.

${ }^{25}$ The universal presupposition (58b) is probably too strong. See Beaver (2001) and Sudo (2012; 2014b) and references therein for ways to weaken it.

${ }^{26}$ We will not discuss languages that allow GENDER mismatches within the same DP, as such cases are unattested in Greek. See Corbett (1991); Wechsler \& Zlatić (2003); Matushansky (2013); Pesetsky (2013); Puškar (2017; 2018); Murphy et al. (2018). In any case, there does not seem to be cases of such GENDER mismatches involving multiple interpreted GENDERs.
} 
occurrences appearing on determiners and adjectives, as suggested by Sauerland (2003; $2008 \mathrm{~b}$ ). This is depicted in the following diagrams, where $[i F]$ is an interpretable occurrence of feature $F$ and $[u F]$ is an uninterpretable one. The dotted lines indicate syntactic agreement.
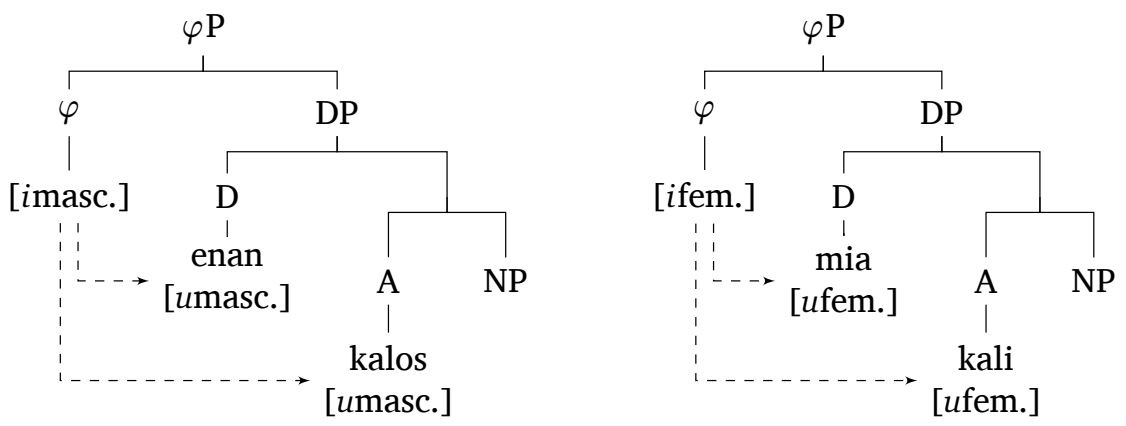

The interpretable GENDER features have the following semantics: ${ }^{27}$
a. $\llbracket[$ imasculine $] \rrbracket=\lambda x \cdot x$
b. $\quad \llbracket[i f e m i n i n e] \rrbracket=\lambda x_{e}: \operatorname{female}(x) \cdot x$

As far as we can see, which analysis to adopt is inconsequential for our main claims. It is crucial that determiners and adjectives never give rise to gender inferences in the assertive dimension of meaning, but this is consistent with both analyses above, but if our denotations for nouns are on the right track, this will entail that not all exponents of GENDER can be given the same analysis (contra Sauerland 2008b; see also Percus 2011), because according to our analysis of nouns, only some of them have gender inferences in their assertive meaning. Why this is so is an interesting question that we cannot fully answer now, but we would like to stress that there is empirical evidence to believe that this is the case, to which we now turn.

\subsection{The semantics of GENDERed nouns}

Recall our implementation of Merchant's (2014) idea about nouns with and without gender inferences, repeated here.

(47) a. $\quad \llbracket$ adherfos $\rrbracket=\lambda x_{e}: \operatorname{male}(x) \cdot \operatorname{male}(x) \wedge \operatorname{sibling}(x)$

b. $\quad \llbracket$ adherfi $\rrbracket=\lambda x_{e}$ : female $(x)$. female $(x) \wedge \operatorname{sibling}(x)$

$$
\llbracket \mathrm{jatros} \rrbracket=\lambda x_{e} \cdot \operatorname{doctor}(x)
$$

$$
\begin{aligned}
& \text { a. } \llbracket \text { dhaskalos } \rrbracket=\lambda x_{e} \cdot \operatorname{teacher}(x) \\
& \text { b. } \llbracket \text { dhaskala } \rrbracket=\lambda x_{e}: \operatorname{female}(x) . \text { female }(x) \wedge \text { teacher }(x)
\end{aligned}
$$

We argued above that [MASCULINE] is generally semantically gender-neutral in Greek, but note that we are allowing Class I MASCULINE nouns to have a gender inference. Consequently, there are two types of MASCULINE nouns in our analysis: semantically MASCULINE ones like adherfos and semantically neutral ones like dhaskalos. Although their semantics

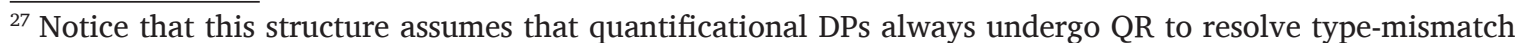
with the GENDER feature, which potentially gives rise to issues in indefinites in negative contexts. See Sauerland (2003) for discussion.
} 
is distinct, both types of MASCULINE nouns trigger MASCULINE agreement. Similarly, there are two types of FEMININE nouns, namely, ones with a gender inference like adherfi and dhaskali and ones that do not have gender inferences but that occur with determiners and/or adjectives with gender presuppositions.

We will now present two sets of evidence motivating this distinction between nouns with and without gender inferences in their semantics, namely, plural nouns (Section 5.3.1) and negative existential sentences (Section 5.3.2).

\subsubsection{Plural nouns}

Our first evidence for the presence/absence of gender inferences in the nominal semantics comes from plural nouns (cf. Corbett 1991; Bobaljik \& Zocca 2011). The logic here is as follows. The plural morpheme is standardly analyzed as a distributive operator, which is a kind of universal quantifier (cf. Link 1983; Winter 2000). Specifically, it takes the denotation $d$ of a singular noun, and turns it to something that applies to any group of individuals each of whom makes $d$ true. Then it follows that if a singular noun has a gender inference, its plural form will require every member of the group it describes to have that gender, and consequently, it can only be used to describe gender-uniform groups. If a noun has no gender inference, on the other hand, its plural form will say nothing about the gender of the individuals and can therefore be used to describe mixed-gender groups.

Let us go through concrete examples to see that the semantics proposed above are in line with the empirical facts. First, Class I nouns: adherfi 'sibling.M.PL' can only describe groups of male siblings, and adherfes 'sibling.F.PL' groups of female siblings, as demonstrated by (62). ${ }^{28}$
a. \#O Petros ke i Maria ine adherfi tu Jani. the Petros and the Maria are sibling.M.PL the.GEN Janis.GEN '*Petros and Maria are brothers of Janis's.'
b. \#O Petros ke i Maria ine adherfes tu Jani. the Maria and the Petros are sibling.F.PL the.GEN Janis.GEN '*Petros and Maria are sisters of Janis's.'

Compare this to Class III nouns like dhaskalos-dhaskala: The plural MASCULINE noun dhaskali 'teacher.M.PL' can describe mixed-gendered groups, while the plural FEMININE noun dhaskales 'teacher.F.PL' is exclusively used for groups of female teachers.
a. O Petros ke i Maria ine dhaskali stin Katerini. the Petros and the Maria are teachers.M in.the Katerini 'Petros and Maria are teachers in Katerini.'
b. \#O Petros ke i Maria ine dhaskales stin Katerini. the Petros and the Maria are teachers.F in.the Katerini

The crucial difference between (62a) and (63a) shows that adherfos has a lexically specified gender, while dhaskalos is gender-neutral.

\footnotetext{
${ }^{28}$ Importantly, the examples in (62) are not ruled out due to agreement mismatch. Generally, predicational sentences of this kind do not require agreement between the two DPs in Greek, as shown by the grammaticality of (i), where the subject DP is marked FEMININE (on the determiner $i$ ) and the other DP is neuter.
(i) I Maria ine kalo koritsi. the.F Maria is good.N girl.N 'Maria is a good girl.'


Plural Class II nouns can also describe mixed gendered groups, but only if the GENDER on other exponents is MASCULINE, as shown in (64).
a. O Petros ke i Maria ine kali jatri.
the Petros and the Maria are good.M doctors
'Petros and Maria are good doctors.'
b. \#O Petros ke i Maria ine kales jatri.
the Petros and the Maria are good.F doctors

This contrast also makes sense under our assumptions about the interpretation of GENDER on adjectives. The FEMININE adjective in (64b) indicates the presence of a gender presupposition that all members of the group in question are female. This is not met in this example.

To be complete, it should also be shown that dhaskali 'teacher.M.PL' and kali jatri 'good.M doctors' cannot describe groups of female individuals.
a. \#I Elena ke i Maria ine dhaskali stin Katerini. the Elena and the Maria are teachers.M in.the Katerini 'Elena and Maria are teachers in Katerini.'
b. \#I Elena ke i Maria ine kali jatri. the Elena and the Maria are good.M doctors 'Elena and Maria are good doctors.'

This is as expected, given the Principle of Gender Competition. In examples like (65), the FEMININE counterparts are felicitous and convey stronger meanings. Therefore, the use of the gender-neutral MASCULINE forms are blocked, although they are semantically coherent.

\subsubsection{Negative existential sentences}

Negative existential sentences can be used to make the same point. In such contexts, nouns with gender inferences restrict the domain of quantification to be gender-uniform. Since they are in downward entailing contexts, furthermore, this means that they will give rise to weaker entailments. By contrast, nouns without a gender inference will not restrict the domain of quantification, thereby giving rise to stronger inferences.

Starting with Class I nouns adherfos-adherfi, they restrict the domain of quantification to male and female individuals, respectively. Consequently, there is no inference about the opposite gender.

(66) a. O Petros dhen exi kanenan adherfo. the Petros not has no.m sibling.M 'Petros has no brother.' $\quad \nRightarrow$ Petros has no sister

b. O Petros dhen exi kamia adherfi. the Petros not has no.F sibling.F 'Petros has no sister.' $\nRightarrow$ Petros has no brother

On the other hand, we observe an asymmetry with dhaskalos-dhaskala, as in the following examples. In particular, (67a) does entail that Petros has no female teacher in Katerini, unlike (67b), which does not entail that Petros has no male teacher in Katerini. 
the Petros not has no.M teacher.M in.the Katerini

'Petros has no teacher in Katerini.'

$\Longrightarrow$ Petros has no female teacher in Katerini

b. O Petros dhen exi kamia dhaskala stin Katerini. the Petros not has no.F teacher.F in.the Katerini 'Petros has no female teacher in Katerini.'

$\nRightarrow$ Petros has no male teacher in Katerini

Notice that this observation is compatible with the Principle of Gender Competition. That is, it is satisfied with (67a), whenever (67b) cannot be used, i.e. whenever there is at least one male individual in the domain of quantification.

We observe the same contrast with EPICENE nouns, as predicted by the proposed semantics where FEMININE features on determiners and adjectives introduce gender presuppositions, while MASCULINE features on them are semantically empty.

a. O Petros dhen exi kanenan jatro.

the Petros not has no.m doctor

'Petros has no doctor.'

$\Longrightarrow$ Petros has no female doctor

b. O Petros dhen exi kamia jatro.

the Petros not has no.F doctor

'Petros has no female doctor.'

$\nRightarrow$ Petros has no male doctor

Thus, these observations point to the conclusion that dhaskalos 'teacher.M' and jatros 'doctor' have no gender inferences, unlike the other nouns in question.

\subsection{GENDERed nouns in focus constructions}

Strictly speaking, the above two phenomena only motivate the distinction between nouns with and without gender inferences in their semantics, and do not constitute evidence for our claim that gender inferences in the nouns themselves manifest themselves in the assertive component of meaning. This part of the analysis is actually crucial for accounting for the behavior of nouns in focus constructions, which we saw in Section 2.2.

As discussed in Section 4.1, it is independently observed that $\varphi$-presuppositions are generally ignored in focus alternatives, whereas asserted meaning cannot be. What our analysis entails, then, is that nouns with gender inferences in their semantics, having asserted gender inferences, should require focus alternatives to also have gender inferences as well, while nouns without gender inferences in their semantics do not require focus alternatives to have the same gender inference. This is exactly what we observed in Section 2.2.

Let us review the crucial data. According to our analysis, Class I nouns all involve gender inferences and indeed, there is no entailment about the opposite gender in the following examples.

a. Mono o Petros ine adherfos tu Jani. only the Petros is sibling.M the.GEN Janis.GEN

'Only Petros is a brother of Janis'.'

$\nRightarrow$ Maria is not Janis's sister

b. Mono i Maria ine adherfi tu Jani. only the Maria is sibling.F the.GEN Janis.GEN 'Only Maria is a sister of Janis'.' 
This is because the gender inferences in the alternatives make the inference trivial when individuals of the opposite gender are subjects in focus alternatives, e.g. that Maria is not Janis's male sibling is trivially true, and so is that Petros is not Janis's female sibling.

On the other hand, Class II nouns do not have gender inferences in their semantics, and as expected, we do observe entailments about the opposite gender in the following examples.

a. Mono o Petros ine kalos jatros. only the Petros is good.M doctor 'Only Petros is a good doctor.' $\Longrightarrow$ Maria is not a good doctor

b. Mono i Maria ine kali jatros. only the Maria is good.F doctor 'Only Maria is a good doctor.'

$\Longrightarrow$ Petros is not a good doctor

In these cases the gender inferences are ignored in the alternatives, so the sentences have these entailments.

Finally, for Class III nouns, we observe an asymmetry, as expected.
a. Mono o Petros ine dhaskalos. only the Petros is teacher.M 'Only Petros is a teacher.'

b. Mono i Maria ine dhaskala. only the Maria is teacher.F 'Only Maria is a teacher.'
$\Rightarrow$ Maria is not a teacher

$\nRightarrow$ Petros is not a teacher

Data involving other focus constructions can be explained in similar ways.

\section{Concluding remarks and further issues}

To summarize, we have closely reviewed Merchant's (2014) observations and raised some additional data to make two new points. First, our data with focus constructions provide further and empirically clearer support for his claim that there are three classes of interpreted MASCULINE-FEMININE pairs in Greek. Second, his generalization that nominal ellipsis with GENDER mismatch is unavailable in argument position is not empirically warranted.

We then evaluated his analysis of nouns with interpreted GENDER in light of our newly raised data and pointed out some assumptions that are not well motivated. In particular, his theory does not give a straightforward explanation of our observations about focus constructions. We take this observation to be suggesting that focus constructions are more informative about the semantics of nouns, and we proposed an alternative analysis by implementing the distinction between asserted vs. presupposed gender, building on the the idea of unmarked GENDER and gender competition. According to our analysis when a noun has a gender inference in its semantics, the gender inference is both presupposed and asserted, and when a noun doesn't have a gender presupposition in its semantics, it simply has no gender inference anywhere in its denotation, but can either get a gender presupposition from other exponents of GENDER in the nominal structure and/or via gender competition. ${ }^{29}$

\footnotetext{
${ }^{29}$ We expect this to be the case across languages. However, an apparent problem comes from nouns like médico 'male doctor' and médica 'female doctor' in Brazilian Portuguese. Bobaljik \& Zocca (2011) present data that show that they behave like EPICENE nouns with respect to nominal ellipsis with gender mismatches,
} 
We would like to clarify what aspects of our analysis are theoretically novel. As we already remarked, the idea of gender competition in the domain of nouns with interpreted GENDER is not new and core ideas can be found in previous works such as Percus (2011) and Sauerland (2003; 2008b). Percus (2011), in particular, proposes the mechanism of gender competition for Italian nouns, and also claims that FEMININE nouns in Italian have asserted gender inferences (contrary to Sauerland 2003; 2008b; Merchant 2014 for whom the semantic contributions of gender features are always presuppositional; see also Kučerová 2018 for a recent account of GENDER in Italian). Unlike us, however, Percus assumes that MASCULINE nouns never have gender inferences. We presented evidence to postulate two types of MASCULINE nouns, those with gender inferences, e.g. adherfos 'male sibling', and those without, e.g. dhaskalos 'male teacher'.

Our claim about nouns with asserted gender inferences also has further consequences. It is often assumed that GENDER features on various exponents have the same semantic contributions (Sauerland 2003; 2008b; Bobaljik \& Zocca 2011; Merchant 2014), but our observations point to the conclusion that GENDER features on nouns sometimes result in asserted inferences, while those on determiners and adjectives never do. However, whether this is indeed the case in other languages is left open for another occasion. In what follows we will mention other further questions that emerge from our proposal.

\subsection{Internal syntax of nouns with GENDER}

We took our observation to motivate the particular semantic variation we proposed among nouns with interpreted GENDER in Greek but we think it shows us very little about their internal syntax. Throughout the paper we have been speaking as if relevant nouns are listed in the lexicon as they are, but this is not to exclude the possibility that these nouns are decomposable into smaller components. For instance, it is perfectly compatible with our proposal to assume that adherfos decomposes into the root adherf- and some functional node (e.g. $n$ ) that hosts the GENDER feature. We remain uncommitted to the internal syntax of the nouns under discussion, especially the exact location of the GENDER feature, as this is currently an actively debated topic (see Wechsler \& Zlatić 2003; Sauerland 2008b; Matushansky 2013; Pesetsky 2013; Kramer 2014; 2015; Puškar 2015; 2017; 2018; Fathi \& Lowenstamm 2016 and references therein). Luckily, none of the arguments we make in this paper hinges on a particular theory of it. We discuss related points in another paper, Spathas \& Sudo (to appear).

\subsection{Nouns under ellipsis}

Recall now that we mentioned in Section 4.1 that ellipsis also ignores $\varphi$-presuppositions, similarly to focus constructions, in the sense that mismatches in $\varphi$-presuppositions are tolerated. Furthermore, it can be observed that assertive meaning is not ignored in ellipsis, as in (69).

Mary met five female linguists. *John met six male linguists.

while having morphological GENDER marking on the nouns themselves. However, we can accommodate them by following Bobaljik \& Zocca's (2011) idea that the GENDER morphology on these nouns is not part of nouns themselves, but something akin to the GENDER morphology on determiners and adjectives. There are several ways to implement this idea. For instance, they could be agreement reflexes with some other item, or alternatively, they could be realizations of some functional projection carrying a gender presupposition. As Bobaljik \& Zocca remark, the fact that the GENDER endings - $o$ and - $a$ appear on a number of non-nominal items in Brazilian Portuguese, including determiners and adjectives, is suggestive of an analysis along these lines. 
Generally, identity up to $\varphi$-presuppositions is required across various elliptical phenomena. ${ }^{30}$ Our denotations of nouns with interpreted GENDER make the predictions that partially match Merchant's (2014) data of nominal ellipsis.

That is, Class I nouns like adherfos and adherfi have gender inferences in the assertive dimension of their sematnics, so GENDER mismatches should not be tolerated. On the other hand, Class II nouns have no asserted gender inferences, so GENDER mismatches should be tolerated. Recall that the judgments of these cases are relatively clear and we take it that our analysis make good predictions here. The relevant data are repeated from Section 3.

(26) a. *O Petros exi enan adherfo stin Veria, ke exi mia adherfi stin the Petros has a.M brother in.the Veria and has one.F (sister) in.the Katerini.

Katerini

(intended) 'Petros has a brother in Veria, and he has a sister in Katerini.'

b. *O Petros exi mia adherfi stin Veria, ke exi enan adherfo stin the Petros has a.F sister in.the Veria and has one.m (brother) in.the Katerini.

Katerini

(intended) 'Petros has a sister in Veria, and he has a sister in Katerini.'

(27) a. O Petros exi enan jatro stin Veria, ke exi mia jatro stin the Petros has a.M doctor in.the Veria and has one.F (doctor) in.the Katerini.

Katerini

'Petros has a male doctor in Veria, and he has a female doctor in Katerini.'

b. O Petros exi mia jatro stin Veria, ke exi enan jatro stin the Petros has a.F doctor in.the Veria and has one.M (doctor) in.the Katerini.

Katerini

'Petros has a female doctor in Veria, and he has a male doctor in Katerini.'

On the other hand, our analysis does not straightforwardly predict the asymmetric licensing with Class III nouns dhaskalos-dhakala that Merchant (2014) reports. While we failed to replicate such a pattern, it would still be instructive to discuss such data for two reasons. Firstly, our failure to replicate Merchant's data might be due to some independent factors that we failed to control for. In fact, we have no evidence that directly contradicts the data he reports. Secondly, Bobaljik \& Zocca (2011) report similar data in languages like Brazilian Portuguese and we certainly expect our analysis to carry over to these languages (see Kučerová 2018; Murphy et al. 2018; Sprouse et al. 2018 for more data).

The reason why our analysis does not straightforwardly predict asymmetric licensing is because ellipsis involving asymmetric entailment is generally unacceptable, as shown by (70).

(70) a. John invited three linguists. *Bill invited four semantieists.

b. John invited three semanticists. *Bill invited four linguists.

\footnotetext{
${ }^{30}$ But see Dalrymple et al. (1991); Kehler (2002); Merchant (2014); Elliott et al. (2014); Elliott \& Sudo (to appear) for cases where total identity is not required.
} 
According to our analysis the Class III FEMININE noun dhaskala asymmetrically entails the Class III MASCULINE noun dhaskalos both in the assertion and in the presupposition. Then, it is expected that GENDER-mismatching ellipsis with Class III nouns should be generally unacceptable, regardless of which one is the antecedent.

We would like to suggest one possible fix of our analysis to address this potential issue. The idea is to assume that the Principle of Gender Competition does not apply to elided nouns. ${ }^{31}$ Then, we can analyze the data as in (71).
a. O Petros episkefthike enan dhaskalo sti Veria, ke mia the Petros visited one.M teacher.M in.the Veria, and one.F dhaskalo stin Katerini. (teacher.M) in.the Katerini 'Petros visited a male teacher in Veria, and a female teacher in Katerini.'
b. *O Petros episkefthike mia dhaskala sti Veria, ke enan the Petros visited one.F teacher.F in.the Veria, and one.M dhaskala stin Katerini. (teacher.F) in.the Katerini (intended) 'Petros visited a female teacher of his in Veria, and a male teacher in Katerini.'

The ellipses here involve total identity, and the DP with an elided noun has DP-internal GENDER mismatch. What's crucial here is the assumption that such mismatch is tolerated, because the Principle of Gender Competition is not active.

Unsurprisingly, the overt counterparts of these sentences are both utterly unacceptable, as in (72).
a. *O Petros episkefthike enan dhaskalo sti Veria, ke mia the Petros visited one.M teacher.M in.the Veria, and one.F dhaskalo stin Katerini. teacher.M in.the Katerini 'Petros visited a male teacher in Veria, and a female teacher in Katerini.'
b. *O Petros episkefthike mia dhaskala sti Veria, ke enan the Petros visited one.F teacher.F in.the Veria, and one.M dhaskala stin Katerini. teacher.F in.the Katerini (intended) 'Petros visited a female teacher of his in Veria, and a male teacher in Katerini.'

In fact, such DP-internal GENDER mismatches with overt material are generally banned in Greek. Our analysis explains the unacceptability of the sentences in (72) as follows.

\footnotetext{
${ }^{31}$ As an anonymous reviewer reminds us, Bobaljik \& Zocca (2011) also make an additional assumption about ellipsis to account for similar facts in Brazilian Portuguese. However, they do so in order to account specifically for the counterparts of EPICENE nouns, rather than the counterparts of dhaskalos-dhaskala. That is, they take the main theoretical problem to be the symmetric licensing for nouns like médico 'male doctor' vs. médica 'female doctor'. Assuming that their GENDER marking is a morphological reflex of syntactic agreement, they claim that nominal ellipsis with GENDER mismatches is possible with these nouns, because syntactic agreement is not relevant for ellipsis licensing. Our explanation of the behavior of EPICENE nouns is similar to this, although for us, the assumption is that $\varphi$-presuppositions are ignored for the purposes of ellipsis licensing, which is given independent support (and exactly how that should be accounted for is immaterial for our purposes here). Crucially, our claim about ellipsis and the Principle of Gender Competition is qualitatively distinct from Bobaljik \& Zocca's idea.
} 
Although (72a) is semantically perfectly coherent, due to the gender-neutral denotation of dhaskalos, it is ruled out by the Principle of Gender Competition. The other example, (72b), is ruled out by the same principle, because the FEMININE determiner mia is available here. But, crucially, notice that there is simply no way that $(72 b)$ could receive the intended reading, because dhaskala is false of a male individual, due to its semantic entailment.

Coming back to the elliptical cases, the infelicity of (71b), then, is not at all surprising. The explanation is the same as for (72b). This just cannot mean what it should mean. What is surprising is the felicity of (71a). The minimal difference between (71a) and (72a) is whether the noun is overt, and the reason why (72a) is infelicitous is because of the Principle of Gender Competition. Conversely, if the Principle of Gender Competition is made inactive under ellipsis, the sentence should be acceptable. With this auxiliary assumption, therefore, we could explain the asymmetric licensing that Merchant (2014) reports.

Furthermore, it is crucial here that what is elided in (71a) is a MASCULINE noun dhaskalos, which is assumed to have no lexically encoded gender inference. This makes a prediction that when an elided noun with a FEMININE determiner occurs in a focus construction, the interpretation should not be restricted to female individuals. Consider, for example, the following examples:

(73) a. I perisoteri apo emas den ehun dhaskalo stin Katerini. the more from us not have teacher.M in.the Katerini 'Most of us don't have a teacher in Katerini.'

b. Mono i Maria exi mia dhaskalo.

only the Maria has one.F (teacher.M) 'Only Maria has one.'

The crucial point about (73b) is that it entails that the other relevant people have no teacher, male or female, in Katerini, and, therefore, should be judged false if it turns out that Petros has a male teacher, for example. Furthermore, the following sentence with an overt FEMININE noun is not judged false in such a scenario.

(74) Mono i Maria exi mia dhaskala stin Katerini.

only the Maria has one.F teacher.F in.the Katerini

'Only Maria has a female teacher in Katerini.'

A contrast of the same nature should arise with other focus constructions too, e.g. superlatives:

(75) a. Oli ehume dhaskalo stin Katerini, ala i Maria ehi tin kaliteri all have teacher.M in.the Katerini, but the Maria has the.F best.F dhaskalo.

teacher.M

'We all have a teacher in Katerini, but Maria has the best one.'

b. Oli ehume dhaskalo stin Katerini, ala i Maria ehi tin kaliteri all have teacher.M in.the Katerini, but the Maria has the.F best.F dhaskala stin Katerini. teacher.F in.the Katerini 'We all have a teacher in Katerini, but Maria has the best female teacher in the Katerini.' 
(75a), unlike (75b), should entail that Maria's female teacher is better than anybody else's teacher, including male teachers. Thus, if Petros has a male teacher and if he turns out to be better than Maria's, (75a) is judged false, while (75b) stays true.

These data would constitute strong support for the analysis that what is elided in (71a) is a MASCULINE noun with gender-neutral meaning, even when other items like determiners are overtly marked as FEMININE, and an important consequence of this would be that underlyingly such GENDER mismatching nouns phrases are allowed, if not overtly, in Greek. It should be remarked in this connection that such GENDER mismatching nouns phrases are overtly attested in other languages like Russian (Pesetsky 2013) and Croatian/ Serbian/Bosnian (Wechsler \& Zlatić 2003; Puškar 2017; 2018). Importantly, for the purposes of this paper, we do not have to make commitments about syntactic assumptions as to how such mismatches arise in the syntax, and we simply refer the reader to the works cited here.

However, since the judgments of GENDER-mismatching ellipsis with Class III nouns are generally not stable with our informants, we could not test these predictions. If the judgments of examples like (71) are stable in languages like Brazilian Portuguese, the above prediction should be testable there. But we have to leave this open for now.

\subsection{On the proform $e_{N}$ and some remarks on uninterpreted GENDER}

Notice at this point that we assumed above without argument that the mechanism for nominal ellipsis in Greek is PF-deletion. Recall that Merchant (2014) postulated another mechanism, namely, the proform $e_{N}$. We could actually account for the main data with $e_{N}$ instead, for the following reasons. ${ }^{32}$ Recall that we assumed total identity under ellipsis, in particular total semantic identity. But $e_{N}$ would also force total semantic identity, because by assumption it has the same denotation as the antecedent noun.

That said, there are several reasons to favor the PF deletion account. Firstly, as we saw in 4.2, extraction from nominal ellipsis site is generally possible, which suggests that the ellipsis site has an internal syntactic structure, and so PF-deletion is at least possible.

Our second argument comes from grammatical gender. Greek has several neuter nouns that refer to humans, e.g. koritsi 'girl', melos 'member', pedhi 'child', agori 'boy' (cf. Spathas 2010; see also Wurmbrand 2016). As mentioned briefly in Section 1, we treat them as involving uninerpreted GENDER. As Merchant (2014) observes, ellipsis with GENDER mismatches is not possible at all with these nouns (for any speaker), as demonstrated by (76) (see also Merchant's 2014 (71)).

(76) *I Eleni ine ena kalo koritsi, ala i Maria ine mia kakia koritsi. the Eleni is a.N good.N girl.N, but the Maria is a.F bad.F (girl.N) (intended) 'Eleni is a good girl, but Maria is a bad one.'

The unacceptability of (76) does not immediately follow from our analysis above, because the structure of the sentence is essentially identical to cases like (71). Notice also that all the gender presuppositions should be satisfied in this sentence. However, it seems to us that there is an independent constraint that specifically targets uninterpreted GENDER and forces DP-internal concord even under ellipsis. This rules out (76), because the second conjunct here involves a NEUTER noun but the determiner and adjective in the same DP bear FEMININE.

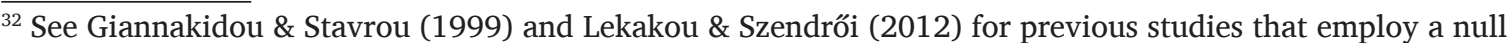
pro-form to account for nominal ellipsis in Greek. See also Lobeck (2006); Saab (to appear) and references therein for various theoretical positions regarding nominal ellipsis in English and other languages.
} 
Now, if $e_{N}$ is available, this analysis will be no longer available. Since $e_{N}$ must be compatible with any GENDER in principle, it should be able to appear with a determiner and/ or adjective carrying a FEMININE feature, given that nominal ellipsis with GENDER mismatches is possible with EPICENE nouns and with dhaskalos-dhaskala when dhaskalos is the antecedent. Moreover, there's no reason why it cannot refer back to the meaning of koritsi 'girl' in (76). Then, (76) is wrongly ruled in. In fact, Merchant (2014) leaves (76) as an open problem that is unaccounted for in his theory. On the other hand, our analysis with PF deletion has at least something to say about this data point, namely, syntax treats interpreted GENDER and uninterpreted GENDER differently, although morphology seems to conflate them. Analyses along these lines have in fact been put forward by some previous studies, such as Alexiadou (2004); Kramer (2014; 2015) and Kučerová (2018). We also propose a view based on the proposal in this paper in Spathas \& Sudo to appear), and we refer the interested readers to these works.

\subsection{Classification of GENDERed nouns}

We have largely put aside the issue of which noun pairs with interpreted GENDER fall into which of the three classes. There are several reasons for this. For one, apart from the robust generalization that all EPICENE nouns lack gender inferences in their semantics, there does not seem to be other stable morphological or syntactic cues as to which nouns have gender inferences and which nouns don't in Greek (see, however, Bobaljik \& Zocca 2011 for the potential relevance of morphology in Brazilian Portuguese and other languages). For instance, adherfos and dhaskalos share the suffix -os, but their GENDERs do not have the same semantic status. In fact, which nouns belong to Class I vs. Class III seems to be a point of inter-speaker variation (see Bobaljik \& Zocca 2011 and Merchant 2014: fn. 6 for related remarks).

Furthermore, there does not seem to be a solid semantic predictor, either. As Bobaljik \& Zocca (2011) point out for other languages, there seems to be a tendency for kinship terms to belong to Class I, but there are some exceptions to this in Greek (at least for some speakers), e.g. thios-thia 'uncle, aunt' seems to be in Class III. Thus, the semantics, although arguably relevant, is not the only factor, either (pace Bobaljik \& Zocca 2011). At the moment, we have nothing insightful to say about this issue.

As mentioned repeatedly, there are other languages that seem to have the same three classes, e.g. Brazilian Portuguese (Bobaljik \& Zocca 2011). It is of particular interest here that the Brazilian Portuguese counterparts of Greek EPICENE nouns have separate MASCULINE and FEMININE forms, e.g. médico 'male doctor' and médica 'female doctor'. What this entails is that there can be MASCULINE-FEMININE noun pairs where both nouns lack lexically specified GENDERs (at least in the assertion) in some languages, although no such nouns are found in Greek. Bobaljik \& Zocca's data also suggest that class assignment is crosslinguistically variable and is unpredictable from the semantics alone. For instance, tio-tia 'uncle, aunt' in Brazilian Portuguese seems to belong to Class I, but the corresponding nouns in Greek belongs to Class III (although the data are potentially muddled by the possibility of inter-speaker variation, as noted above). These issues lead also to important questions concerning the acquisition of nouns and their class assignment, but questions like these are far beyond the purview of the present paper (see Sprouse et al. 2018).

Relatedly, there seems to be a gap in the paradigm, at least, in Greek in that there is no MASCULINE-FEMININE pair that has a gender inference only on the MASCULINE noun (i.e. the opposite of dhaskalos-dhaskala). This is likely to be due to the general unmarkedness of MASCULINE relative to FEMININE in Greek, but nothing in our analysis excludes such a pair. Although we will not try to capture the absence of such pairs of nouns in Greek, 
we would like to note that there seem to be languages where FEMININE is less marked than MASCULINE (see Corbett 1991: Ch.7, Kramer 2015: Ch.5; see also Bosnian/Serbian/ Croatian data reported in Puškar 2017; 2018; Murphy et al. 2018), and there might well be pairs where the MASCULINE noun has a gender inference and the FEMININE noun does not (see Percus 2011 for related discussion). Whether this is so is left unanswered here as well.

\subsection{Cases with no gender competition}

We mentioned in fn. 25 the existence of gender-neutral nouns that have gender-specific counterparts but do not seem to compete with them. For instance, for many speakers of contemporary English, actor can be used gender-neutrally, although it has a morphologically related FEMININE form actress. Thus, for these speakers, we observe the following pattern of judgments.
a. Mary is an actor.
b. Mary is an actress.
c. John is an actor.
d. \#John is an actress.

If the Principle of Gender Competition applied to actor-actress, (77a) should be ruled out. Thus, this indicates that actor somehow does not compete with actress.

In Greek, one can find such nouns in the domain of animal-denoting nouns (although not among human-denoting nouns). For instance, jata is grammatically a FEMININE noun, but commonly used to describe both female and male cats. In addition to this noun, there is a gender-specific noun jatos, which is exclusively used for male cats. Concretely, from (78), one cannot infer the gender of the cat that Maria bought, but one can infer that Kostas bought a male cat.

$$
\begin{aligned}
& \text { a. I Maria ajorase mia jata. } \\
& \text { the Maria bought a.F cat.F } \\
& \text { 'Maria bought a cat.' } \\
& \text { b. O Kostas ajorase enan jato. } \\
& \text { the Kostas bought a.M cat.M } \\
& \text { 'Kostas bought a male cat.' }
\end{aligned}
$$

Just as in the case of actor-actress, if jata and jatos competed, one should infer from (78a) that Maria bought a female cat. Thus, again, jata does not seem to compete with jatos.

The immediate question that arises is why these nouns are exempt from gender competition. We would like to suggest here that the gender-neutral member of these pairs has uninterpreted GENDER, and the Principle of Gender Competition does not apply to uninterpreted GENDER. Specifically, we analyze jata 'cat.F' as having uninterpreted GENDER. In fact, we observe that the jata-jatos pair does not allow nominal ellipsis with GENDER mismatches, just like in the case of koritsi 'girl.N' in (76).

a. I Maria ajorase mia mavri jata. O Kostas mia aspri jata. the Maria bought a.F black.F cat.F. the Kostas a.F white.F (cat.F) 'Maria bought a black cat. Kostas bought a white one.'

b. I Maria ajorase mia mavri jata. *O Kostas enan aspro jata. the Maria bought a.F black.F cat.F. the Kostas a.M white.M (cat.F)

We spell out more details of this idea in Spathas \& Sudo (to appear). 
Extending this idea to English, actor (for certain speakers) could be analyzed as having uninterpreted GENDER. There are, however, some more complications here. In particular, actor can bound a FEMININE pronoun, as in (80).

Only this actor is satisfied with her film career.

One might take this as showing that actor has an interpreted GENDER. However, as Spathas (2010) observes, GENDER mismatches in pronominal binding are possible, at least in some languages, if not universally. As shown in (81), to koritsi 'the girl', which is NEUTER, can bind a FEMININE pronoun in Greek (see Wurmbrand 2016).

Mono to koritsi vjike apo to spiti tu / tis. only the.N girl.N exited from the house its.N / her.F 'Only the girl left her house.'

Under the bound reading of the pronoun, this entails that other relevant people (e.g. boys) did not leave their houses. Thus, the example in (80) does not convincingly show that the GENDER on actor is not uninterpreted.

Thus, there is a puzzling contrast between koritsi 'girl' and jata 'cat'. The latter does not allow for GENDER mismatching pronominal binding.

$$
\begin{aligned}
& \text { Mono i jata vjike apo to spiti tis / *tu. } \\
& \text { only the.F cat.F exited from the house her.F / *his.M } \\
& \text { 'Only the cat left her house.' }
\end{aligned}
$$

This observation suggests that there is something fundamentally different between uninterpreted GENDER on human-denoting nouns and animal-denoting nouns, at least in Greek. We address this and related issues in a separate paper (Spathas \& Sudo to appear).

\section{Abbreviations}

$\mathrm{F}=$ feminine, $\mathrm{GEN}=$ genitive, $\mathrm{M}=$ masculine, $\mathrm{N}=$ neuter, $\mathrm{PL}=$ plural

\section{Acknowledgements}

We would like to thank Maria Barouni, Stergios Chatzikyriakidis, Stella Gryllia, Petros Karatsareas, Dimitra Lazaridou-Chatzigoga, Marika Lekakou, Dimitris Michelioudakis, and Despina Oikonomou for judgments, and Artemis Alexiadou, Patrick D. Elliott, Dimitra Lazaridou-Chatzigoga, Andrew Nevins, Orin Percus, and three anonymous reviewers for Natural Language and Linguistic Theory and three anonymous reviewers for Glossa for helpful discussion and useful comments. We also benefitted from comments from the audiences of the Syntax Reading Group at University College London on 10 December, 2014, the Agreement Across Borders Workshop at the University of Zadar on 15 June, 2015, Sinn und Bedeutung on 11 September, 2015, and ZAS on October 28, 2015. All errors are our own.

\section{Competing Interests}

The authors have no competing interests to declare.

\section{References}

Abrusán, Márta. 2011. Predicting the presuppositions of soft triggers. Linguistics and Philosophy 34(6). 491-535. DOI: https://doi.org/10.1007/s10988-012-9108-y 
Alexiadou, Artemis. 2004. Inflection class, gender and DP-internal structure. In Gereon Müller, Lutz Gunkel \& Gisela Zifonun (eds.), Explorations in Nominal Inflection, 21-50. Berin: de Gruyter. DOI: https://doi.org/10.1515/9783110197501.21

Anvari, Amir. 2019. Aspects of Contextual Enrichment. Ecole Normale Supérieure dissertation.

Beaver, David. 2001. Presupposition and Assertion in Dynamic Semantics. Stanford: CSLI.

Bobaljik, Jonathan \& Cynthia Zocca. 2011. Gender markedness: The anatomy of a counter-example. Morphology 21(2). 141-166. DOI: https://doi.org/10.1007/s11525-0109156-3

Büring, Daniel. 1997. The great scope inversion conspiracy. Linguistics and Philosophy 20(2). 175-194. DOI: https://doi.org/10.1023/A:1005397026866

Büring, Daniel. 2003. On D-trees, beans, and B-accents. Linguistics and Philosophy 26(5). 511-545. DOI: https://doi.org/10.1023/A:1025887707652

Büring, Daniel. to appear. (Contrastive) Topic. In Caroline Féry \& Shinichiro Ishihara (eds.), The Handbook of Information Structure. Oxford: Oxford University Press.

Cooper, Robin. 1983. Quantification and Semantic Theory. Dordrecht: Reidel.

Corbett, Greville G. 1991. Gender. Cambridge: Cambridge University Press.

Dalrymple, Mary, Stuart M. Shieber \& Fernando C. N. Pereira. 1991. Ellipsis and higherorder unification. Linguistics and Philosophy 14(4). 399-452. DOI: https://doi. org/10.1007/BF00630923

Elliott, Patrick D. Andreea Nicolae \& Yasutada Sudo. 2014. The sticky reading: VP ellipsis without parallel binding. In Todd Snider (ed.), Proceedings of SALT 24. 640-655. LSA. DOI: https://doi.org/10.3765/salt.v24i0.3639

Elliott, Patrick D. \& Yasutada Sudo. to appear. E-type readings of quantifiers under ellipsis. In Proceedings of Sinn und Bedeutung 20.

Fathi, Radwa \& Jean Lowenstamm. 2016. The gender assignment pattern of French nouns. Morphology. DOI: https://doi.org/10.1007/s11525-016-9287-2

Fiengo, Robert \& Robert May. 1994. Indices and Identity. Cambridge, MA: MIT Press.

Gazdar, Gerald. 1979. Pragmatics: Implicature, Presupposition, and Logical Form. Academic Press.

Giannakidou, Anastasia \& Melita Stavrou. 1999. Nominalization and ellipsis in the Greek DP. The Linguistic Review 16(4). 295-332. DOI: https://doi.org/10.1515/ tlir.1999.16.4.295

Heim, Irene. 1982. The Semantics of Definite and Indefinite Noun Phrases. University of Massachusetts, Amherst Ph.D. dissertation.

Heim, Irene. 1983. On the projection problem for presuppositions. In WCCFL 2. 114-125.

Heim, Irene. 1991. Artikel und Definitheit. In Arnim von Stechow \& Dieter Wunderlich (eds.), Semantik: Ein internationales Handbuch der zeitgenössischen Forschung/Semantics: An International Handbook of Contemporary Research, 487-535. Berlin: de Gruyter.

Heim, Irene. 2008. Features on bound pronouns. In Daniel Harbour, David Adger \& Susana Bejar (eds.), Phi Theory: Phi-Features Across Modules and Interfaces, 35-56. Oxford: Oxford University Press.

Heim, Irene \& Angelika Kratzer. 1998. Semantics in Generative Grammar. Oxford: Blackwell.

Jacobson, Pauline. 2012. The direct compositionality and "uninterpretability": The case of (sometimes) "uninterpretable" features on pronouns. Journal of Semantics 29(3). 305-343. DOI: https://doi.org/10.1093/jos/ffs005

Jakobson, Roman. 1984. Structure of the Russian verb. In Linda R. Waugh \& Morris Halle (eds.), Russian and Slavic Grammar: Studies 1931-1981, chap. 1, 1-14. Mouton. DOI: https://doi.org/10.1515/9783110822885.1 
Johnson, Kyle. 2001. What VP-ellipsis can do, what it can't, but not why. In Mark Baltin \& Chris Collins (eds.), The Handbook of Contemporary Syntactic Theory, 439-479. Oxford: Blackwell. DOI: https://doi.org/10.1002/9780470756416.ch14

Johnson, Kyle. 2014. Commentary on 'Gender mismatches under nominal ellipsis' by Jason Merchant. Lingua 151. 33-42. DOI: https://doi.org/10.1016/j.lingua.2014.06.003

Kehler, Andrew. 2002. Coherence, Reference, and the Theory of Grammar. Stanford, CA: CSLI.

Kramer, Ruth. 2014. Gender in Amharic: a morphosyntactic approach to natural and grammatical gender. Language Sciences 43. 102-115. DOI: https://doi.org/10.1016/j. langsci.2013.10.004

Kramer, Ruth. 2015. The Morphosyntax of Gender. Oxford: Oxford University Press. DOI: https://doi.org/10.1093/acprof:oso/9780199679935.001.0001

Kratzer, Angelika. 1998. More structural analogies between pronouns and tenses. In Proceedings of SALT 8. 92-109. DOI: https://doi.org/10.3765/salt.v8i0.2808

Kratzer, Angelika. 2009. Making a pronoun: fake indexicals as windows into the properties of pronouns. Linguistic Inquiry 40(2). 187-237. DOI: https://doi.org/10.1162/ ling.2009.40.2.187

Kučerová, Ivona. 2018. $\phi$-features at the syntax-semantics interface: Evidence from nominal inflection. Linguistic Inquiry 49(4). 813-845. DOI: https://doi.org/10.1162/ ling_a_00290

Lekakou, Marika \& Kriszta Szendrői. 2012. Polydefinites in Greek: Ellipsis, close apposition and expletive determiners. Journal of Linguistics 48(1). 107-149. DOI: https://doi. org/10.1017/S0022226711000326

Link, Godehard. 1983. The logical analysis of plurals and mass terms: A lattice theoretical approach. In Rainer Bäuerle, Christoph Schwarze \& Arnim von Stechow (eds.), Meaning, Use, and the Interpretation of Language, 302-323. Berlin: Mouton de Gruyter.

Lobeck, Anne. 2006. Ellipsis in DP. In Martin Everaert \& Henk van Riemsdijk (eds.), The Blackwell Companion to Syntax 1. 145-173. Malden: Blackwell. DOI: https://doi. org/10.1002/9780470996591.ch22

Markopolous, Giorgos. 2018. Phonological Realisation of Morphosyntactic Features. Aristotle University of Thessaloniki dissertation.

Marty, Paul P. 2017. Implicatures in the DP Domain. Massachusetts Institute of Technology dissertation.

Matushansky, Ora. 2013. Gender confusion. In Lisa Cheng \& Norbert Corver (eds.), Diagnosing Syntax, 271-294. Oxford: Oxford University Press. DOI: https://doi.org/10.1093/ acprof:oso/9780199602490.003.0013

McConnell-Ginet, Sally. 2011. Gender, Sexuality, and Meaning: Linguistic Practice and Politics. Oxford: Oxford University Press.

Merchant, Jason. 2014. Gender mismatches under nominal ellipsis. Lingua 151. 9-32. DOI: https://doi.org/10.1016/j.lingua.2014.01.008

Murphy, Andrew, Zorica Puškar \& Matías Guzmán Naranjo. 2018. Gender encoding on hybrid nouns in Bosnian/Croatian/Serbian: Experimental evidence from ellipsis. In Denisa Lenertová, Roland Meyer, Radek Šimík \& Luka Szucsich (eds.), Advances in formal slavic linguistics 2016, 313-336. Berlin: Language Science Press.

Pavilidou, Theodossia-Soula. 2015. Gender and the greek language. Gender and Language 9(1). DOI: https://doi.org/10.1558/genl.v9i1.26938

Percus, Orin. 2006. Antipresuppositions. Tech. rep. Japan Society for the Promotion of Science. Report of the Grant-in-Aid for Scientific Research (B), Project No. 15320052.

Percus, Orin. 2010. Antipresuppositions revisited. Talk given at CRISCO, Université de Caen. 
Percus, Orin. 2011. Gender features and interpretation: a case study. Morphology 21(2). 167-196. DOI: https://doi.org/10.1007/s11525-010-9157-2

Pesetsky, David. 2013. Russian Case Morphology and the Syntactic Categories. Cambridge, MA: MIT Press. DOI: https://doi.org/10.7551/mitpress/9780262019729.001.0001

Puškar, Zorica. 2015. Interactions of gender and number agreement: Evidence from bosnian/croatian/serbian. Ms., University of Leipzig.

Puškar, Zorica. 2017. Hybrid Agreement: Modelling Variation, Hierarchy Effects and Phi- Features Mismatches. University of Leipzig dissertation.

Puškar, Zorica. 2018. Interactions of gender and number agreement: Evidence from Bosnian/Croatian/Serbian. Syntax 21(3). 275-318. DOI: https://doi.org/10.1111/ synt.12154

Ralli, Angela. 2002. The role of morphology in gender determination: evidence from Modern Greek. Linguistics 40(3). 519-551. DOI: https://doi.org/10.1515/ling.2002.022

Ross, John. 1967. Constraints on Variables in Syntax. Massachusetts Institute of Technology dissertation.

Saab, Andrés. to appear. Nominal Ellipsis. In Tanja Temmerman \& Jeroen van Craenenbroeck (eds.), The Oxford Handbook of Ellipsis. Oxford: Oxford University Press.

Sauerland, Uli. 2003. A new semantics for number. In Robert B. Young \& Yuping Zhou (eds.), Proceedings of SALT 13. 258-275. Ithaca, NY: Cornell Linguistics Club. DOI: https://doi.org/10.3765/salt.v13i0.2898

Sauerland, Uli. 2008a. Implicated presuppositions. In Anita Steube (ed.), The Discourse Potential of Underspecified Structures (Language, Context and Cognition), 581-600. Berlin: Mouton de Gruyter.

Sauerland, Uli. 2008b. On the semantic markedness of phi-features. In Daniel Harbour, David Adger \& Susana Béjar (eds.), Phi Theory: Phi-Features across Modules and Interfaces, 57-82. Oxford: Oxford University Press.

Sauerland, Uli. 2013. Presuppositions and the alternative tier. In Proceedings of SALT 23. 156-173. DOI: https://doi.org/10.3765/salt.v23i0.2673

Schlenker, Philippe. 2009. Local contexts. Semantics and Pragmatics 2. 1-78. DOI: https:// doi.org/10.3765/sp.2.3

Schwarz, Bernhard. 2000. Topics in Ellipsis. University of Massachusetts, Amherst dissertation.

Singh, Raj. 2011. Maximize Presupposition! and local contexts. Natural Language Semantics 19(2). 149-168. DOI: https://doi.org/10.1007/s11050-010-9066-2

Spathas, Giorgos. 2010. Focus on Anaphora. Universiteit Utrecht Ph.D. dissertation.

Spathas, Giorgos \& Yasutada Sudo. to appear. Gender on animal nouns in Greek. Catalan Journal of Linguistics .

Spector, Benjamin \& Yasutada Sudo. 2017. Presupposed ignorance and exhaustification: how scalar implicatures and presuppositions interact. Linguistics and Philosophy 40(5). 473-517. DOI: https://doi.org/10.1007/s10988-017-9208-9

Sprouse, Jon, Troy Messick \& Jonathan Bobaljik. 2018. Gender asymmetries in ellipsis: an experimental comparison of markedness and frequency accounts. Ms., University of Connecticut, Storrs.

Sudo, Yasutada. 2012. On the Semantics of Phi Features on Pronouns. Massachusetts Institute of Technology Ph.D. dissertation.

Sudo, Yasutada. 2014a. Dependent plural pronouns with Skolemized choice functions. Natural Language Semantics 22(3). 265-297. DOI: https://doi.org/10.1007/s11050014-9107-3

Sudo, Yasutada. 2014b. Presupposition projection in quantified sentences and crossdimensional anaphora. Ms., UCL. 
Wechsler, Stephen \& Larisa Zlatić. 2003. The Many Faces of Agreement. Stanford: CSLI.

Winter, Yoad. 2000. Distributivity and dependency. Natural Language Semantics 8(1). 27-69. DOI: https://doi.org/10.1023/A:1008313715103

Wurmbrand, Susi. 2016. Girls, glasses, and you: The distribution of formal vs. semantic agreement. Talk at GGS, Leipzig.

Yatsushiro, Kazuko \& Uli Sauerland. 2006. [Feminine] in a high position. Snippets 13. 11-12.

How to cite this article: Sudo, Yasutada and Giorgos Spathas. 2020. Gender and interpretation in Greek: Comments on Merchant (2014). Glossa: a journal of general linguistics 5(1): 129.1-42. DOI: https://doi.org/10.5334/gjgl.1173

Submitted: 11 December 2019

Accepted: 08 October 2020

Published: 29 December 2020

Copyright: $\odot 2020$ The Author(s). This is an open-access article distributed under the terms of the Creative Commons Attribution 4.0 International License (CC-BY 4.0), which permits unrestricted use, distribution, and reproduction in any medium, provided the original author and source are credited. See http://creativecommons.org/licenses/by/4.0/.

$\mathrm{u}[\quad$ Glossa: a journal of general linguistics is a peer-reviewed open access journal published by Ubiquity Press.

OPEN ACCESS $\boldsymbol{\sigma}$ 